\title{
Unemployment Dynamics across OECD Countries
}

\author{
Ravi Balakrishnan \\ London School of Economics, CEP \\ Claudio Michelacci \\ CEMFI \\ Working Paper No. 9806 \\ December 1998
}

We are particularly indebted to Charlie Bean, Chris Pissarides and an anonymous referee for very useful suggestions and thorough readings. We also thank Alan Manning, Danny Quah and Etienne Wasmer for very useful conversations as well as the participants in seminars at the Centre for Economic Performance and at the LSE. Last and certainly not least we would like to thank Michael Burda and Charles Wyplosz for making available their data. The usual disclaimer applies. (E-mail addresses: c.michelacci@cemfi.es, r.balakrishnan@lse.ac.uk).

CEMFI, Casado del Alisal 5, 28014 Madrid, Spain.

Tel: 3491 4290551, fax: 3491 4291056, www.cemfi.es. 


\begin{abstract}
The European Community and the US have experienced vastly different unemployment dynamics over the last two decades. This paper investigates whether these differences are due to exposure to different shocks or reacting differently to the same shocks. With the premise of a search theoretic framework and a structural VAR methodology, the paper robustly identifies aggregate versus reallocative shocks. With the exception of Spain where most of the dynamics seems to be driven by reallocation, it is found that most differences in unemployment dynamics arise because of differences in responses to shocks. In particular the US Labour market is quicker to adjust than the European Community. This implies that EEC economies might be dynamically 'sclerotic', even if the size of the steady state labour market flows give the impression that European Labour markets are quite active. Various identifying assumptions, additional labour supply shocks and different variables are used so that the results seem to be robust.
\end{abstract}




\section{Introduction}

Over the last two decades unemployment has increased dramatically within the European Community (EC). It started at less than $3 \%$ of the workforce before the first oil price shock, peaked at $11 \%$ in 1985 and is now around $10 \%$. This phenomenon was not seemingly replicated in the US. The US has also experienced a rise in unemployment over some of this period, but nowhere near as marked as that for the EC. Many theories have been produced to explain the differences in the time path of unemployment between the two sides of the Atlantic. These huge differences in the dynamics of unemployment, however, remain a major puzzle for macroeconomists (see i.e. Bean 1994) where "many suspects have been identified, none has been convicted" (Blanchard and Katz 1996).

Standard macroeconomic theory represents the equilibrium dynamics of an economic variable, as the joint outcome of exogenous structural shocks and a transmission mechanism that allows for these shocks to propagate in the economic system. Equilibrium unemployment has had a very different time path in the European Community and the US. This paper questions whether these differences are due to exposure to either different shocks, or reacting differently to the same shocks or both.

The structural VAR (SVAR) methodology, pioneered among others by Bernanke (1986) and Blanchard and Quah (1989), seems well suited to the above question. In fact, if a structural VAR (SVAR) is estimated, the impulse response functions represent how shocks propagate in the economic system, while the variance decompositions weight the contribution of each shock in the forecasting error of the relevant variables. For the exercise to be meaningful, however, the shocks must have a robust economic interpretation: that is the call for a theoretical framework. We choose a search theoretic one (see i.e. Pissarides 1990) and we use flow data, from and into unemployment (see Burda and Wyplosz 1994), to identify aggregate versus reallocative shocks. An aggregate shock affects the average profitability of jobs: a positive shock will increase the profitability of jobs and thus increase the incentive to cre- 
ate new ones. At the same time, the shock reduces the incentive to destroy the old ones, so that inflows into and from the unemployment pool, tend to move in opposite directions. A reallocative shock on the other hand, affects the dispersion of productivities across jobs. For example, a positive reallocative shock will increase, for a given average productivity, productivity in some firms and will reduce it in others. More jobs will be created in high productivity sectors. At the same time, more jobs will be destroyed in low productivity ones, so that the unemployment flows tend to move in the same direction. We start from a two variable SVAR specification and then augment it by introducing additional labour force shocks, identified as a skill unbiased and a skill biased component. We think of the former, as a shock that in the long run is neutral on the level of the unemployment rate and of the latter as a shock that, for given size of the labour force, affects unemployment flows in the same way as a reallocative shock.

A related exercise was carried out by Blanchard and Diamond (1989, 1990). They estimated a three variable SVAR with unemployment, vacancies and the labour force. Their experiment was carried out for the US only. They found that, except at long durations, reallocative and labour force shocks contributed little to the fluctuations in the unemployment or vacancy rate. This paper differs in three respects. Firstly we make use of flow as well as stock data. In fact, Hosios (1991), Mortensen and Pissarides (1994) and Caballero and Hammour (1994) argue for the need to look at labour market flows to properly identify reallocative versus aggregate shocks. Once the job destruction rate is endogenized it is no longer possible to properly identify these shocks by looking at movements in unemployment and vacancies alone (see Hosios 1991). Secondly, the analysis is cross-country. We estimate SVARS for the US, the UK, Germany, France and Spain for the period 1972-1990 so that the main purpose of the paper is to compare across countries. Lastly, we extensively check for robustness using different structural restrictions, and different variables in our VAR specification.

The main results of the paper can be summarized as follows: 
2 European economies seem to respond slower to the same shock, when compared with the US. This implies that EEC economies might be dynamically "sclerotic" even if the size of the steady state labour market flows might give the impression of the European labour market being quite active (see Burda and Wyplosz 1994, OECD, 1994a, 1994b, Garibaldi et al., 1996, Alogoskoufis et al. 1995 and Bertola and Rogerson 1996).

2 Different economies seem to be subject to the same structural shocks, mainly aggregate ones, with the only exception being Spain where reallocative shocks are predominant. This might be caused by the need of reallocating workers from the agriculture to the manufacturing sectors after the Franco's reign, see Marimon and Zilibotti (1996) and Dolado and Jimeno (1997). Moreover, reallocative shocks account for less in US compared to Europe. A possible explanation is that the US economy is more flexible and therefore it reallocates the labour force across jobs and sectors without causing unemployment so that the contribution of reallocative shocks in forecasting unemployment is low.

2 Skill unbiased labour force shocks do not appear to have much influence for any of the countries considered, so that most structural shocks exhibit permanent effects on the level of the unemployment rate, see Blanchard and Summers (1986).

2 For all countries in the sample, the reallocative component can be split into a labour side skill biased component and a firm side reallocative component. This implies that skill biased technological progress (see Katz and Murphy 1992 and Juhn et al. 1993) might explain some of the unemployment problems of OECD economies.

Section II introduces aggregate and reallocative shocks in a search theoretic framework, and section III summarises the SVAR methodology. Section IV documents the data. Section V reports the results for the two variable 
SVAR under different specifications. Section VI extends the analysis, by introducing labour force shocks into the model and considering both a three and four variable SVAR. Section VII summarises the results and considers the implications.

\section{A Search Theoretic Framework}

In this section we sketch a model of the labour market with search frictions. We use the model to derive the implications of aggregate and reallocative shocks for the dynamics of labour market flows. The analysis draws on Pissarides (1990) and Mortensen and Pissarides (1994).

\subsection{The theoretical Set-up}

In the labor market there are firms and there are workers. We assume they are both risk-neutral and maximize expected returns in output units, discounted at rate $r>0$. Each firm has one job that can be in one of two states, filled and producing or vacant and searching. Jobs that are not actively producing or searching for a match are destroyed. Similarly, workers can be either unemployed and searching or employed and producing. As in Jovanovic $(1979,1984)$ we keep the simplifying assumption of equating wages to marginal product. This implies, as Jovanovic does, that if $h$ is the exogenous amount of output value that the worker is able to earn once unemployed, his wage w once employed will also be equal to $\mathrm{h}^{1}$ :

Each job is characterized by a fixed irreversible technology and produces a quantity of goods equal to $P+3 / 4$. $P$ and $3 / 4$ are common to all jobs. I is job specific and represents an idiosyncratic component of productivity. $P$ is

\footnotetext{
${ }^{1}$ In the search literature wages are usually chosen so as to share at all times the surplus from a job match in fixed proportion, usually via a Nash bargain, see for example Pissarides (1990). We do not pursue this line of research here to save notation and space. The identifying assumption of aggregate versus reallocative shocks does not depend on this simplifying assumption.
} 
an aggregate component of productivity that does not affect the dispersion of productivity. A change in $\mathrm{P}$ affects in a similar way the profitability of all jobs and it is thus called an aggregate shock. The parameter $3 / 4$ reflects dispersion, an increase in $3 / 4$ representing a symmetric mean preserving spread in the job-specific shock distribution or equivalently, an increase in the cross sectional variance of the productivity of jobs. A change in $3 / 4$ is a reallocative shock. For example, an increase in $3 / 4$ corresponds to a positive reallocative shock: productivity in some firms raises while it is reduced in others.

The process that changes the idiosyncratic component of productivity is assumed to be a Poisson process with rate of arrival ${ }^{1}$ : When there is change, the new value of $\boldsymbol{I}$ is a drawing from the fixed distribution $G(\Phi)$ which has finite upper support 7 no mass points, zero mean and unit variance. $3 / 4$ is therefore the standard deviation of the idiosyncratic component of productivity $3 / 4$;

As in Mortensen and Pissarides (1994), firms create jobs that have productivity equal to the upper support of the distribution of productivities $P+3 / 4$ Once a job is created, however, the firm has no choice over its productivity. Thus job productivity is a stochastic process, with initial condition the upper support of the distribution and terminal state the reservation productivity $R$ that leads to job destruction. In fact, existing filled jobs are destroyed only if idiosyncratic component of their productivity falls below some critical number $\mathrm{R}<$ 耼 Therefore, the rate at which existing jobs are destroyed is ${ }^{1} G(R)$ :

As workers are heterogeneous and firms are posting vacancies to operate specific jobs, matching a worker with a vacancy is costly and requires time. Because of this, the model is usually closed through a useful tool: the matching function ${ }^{2}$, that is a stable, concave, homogenous-of-degree-one aggregate

\footnotetext{
${ }^{2}$ See Jackman, Layard and Pissarides (1986), Pissarides (1986), Blanchard and Diamond $(1989,1990)$ and Burda and Wyplosz (1994) for empirical evidence on the existence of stable aggregate matching functions. Caballero and Hammour $(1990,1996)$ show how a matching function is not required to close the model, as a search theoretic framework just asks for some mechanism that makes it progressively less profitable to post vacancies at a given level of unemployment. In their set up, creation costs provide this.
} 
relation, $\mathrm{H}=\mathrm{m}(\mathrm{U} ; \mathrm{V})$; linking the unemployment pool $\mathrm{U}$ and the stock of vacancies, $\mathrm{V}$; with the number of new hirings $\mathrm{H}$. The matching function allows one to represent two key characteristics of the labour market: the fact that workers and firms are heterogeneous so that search is costly and time consuming; and the fact that different firms might compete for the same workers. The transition rate for vacancies is $q(\mu)=\frac{m(U ; V)}{V}=m\left(\frac{U}{V} ; 1\right)=m\left(\frac{1}{\mu} ; 1\right)$; where $\mu=\frac{V}{U}$; while the rate at which unemployed seekers meet vacancies is $p(\mu)=\frac{m(U ; V)}{U}=m(1 ; \mu)$.

\subsection{The Formal Model}

The assumption that vacancies cost $\hat{A}$ per unit of time and that jobs are created at the upper support of the distribution of the productivity distribution imply that

$$
r V=i \hat{A}+q(\mu)[J(7) i V]
$$

where $\mathrm{V}$ and $\mathbf{J}(\mathbf{9})$ are respectively the asset values of a vacancy and of a filled job with idiosyncratic component of As in Pissarides (1990) and Burda and Wyplosz (1994) jobs are created until the exhaustion of all rents. This implies the value of posting a vacancy must reach zero, so that the following free entry condition holds:

$$
\frac{\hat{A}}{q(\mu)}=J(7)
$$

Since firms have the option of closing jobs at no cost, a filled job continues in operation for as long as it is profitable. Hence, filled jobs are destroyed when a productivity shock y arrives that makes J (y) negative. Given the Jovanovic assumption that workers are paid their marginal product $h$; for any realization $q \mathrm{~J}$ ( 9 ) solves the Belman equation

$$
\left(r+{ }^{1}\right) J(\mathbb{D})=P+3 / 4 \pi i h+{ }_{i 1}^{Z_{\text {१ा }}} \max [J(y) ; 0] d G(y):
$$

Since $\mathrm{J}(\mathbb{9})$ is monotonically increasing in $\mathbb{f}$ there is a unique reservation productivity $R$ that solves $\mathrm{J}(\mathrm{R})=0$ such that jobs that get a shock $\mathbb{\mathrm { N }}<\mathrm{R}$ 
are destroyed. The condition $J(R)=0$ and the fact that $\left.\int q y\right)=\frac{3 / 4}{r++^{1}}$, implies after integration by parts that $\mathrm{R}$ solves

$$
P+3 / R=h i \frac{3 / 4}{r+1}_{R}^{Z_{\eta}}[1 ; G(y)] d y
$$

so that 81 > R

$$
J(\Phi)=3 / \frac{\left(q_{i} R\right)}{1+r}
$$

while $J(\mathbb{9})=0$ if $\mathbb{9} \quad R$ : Equation $(F E)$ together with (DE) given the constraint imposed by either (1) or (2) completely solves the model in the two endogenous variables, $\mu$ and $\mathrm{R}$ : Given equation (F E ), $\mu$ reflects market pro..tability: the bigger the profitability of a job the bigger the incentive to enter the market and the higher is $\mu . R$ is a reservation productivity and reflects the option of firms to keep operating: the bigger the value of the option, the lower the value of $\mathrm{R}$ :

Let us indicate respectively with $E_{t}$ and $U_{t}$, the number of employed and unemployed workers. We then obtain that the inflow into unemployment, in; and the outflow from unemployment, out; are equal to

$$
\begin{aligned}
\text { in } & ={ }^{1} G(R) E_{t} \\
\text { out } & =p(\mu) U_{t}:
\end{aligned}
$$

${ }^{1} G(R)$ is the inflow rate into unemployment. It is increasing in $R$ : the higher the reservation productivity $R$, the bigger the fraction of firms that are destroyed. $P(\mu)$ is the outflow rate from unemployment. It is increasing in $\mu$ : the bigger the value of $\mu$; the higher the probability of exiting from the unemployment pool.

In this framework, it is possible to think of shocks affecting either firms or the labour force. In this section we focus on shocks of the first kind, while we analyze shocks of the second kind in section VI.

An aggregate shock affects in a similar way the profitability of all jobs both the operating and non operating ones, this is equivalent to a change in 
$P$. Differentiating $(F E)$ and $(D E)$ with respect to $P$ it can be seen that

$$
\begin{aligned}
& \frac{d R}{d P}=i \frac{3 / 41}{1 i \frac{1}{r+^{1}}[1 ; G(R)]}<0 \\
& \frac{d \mu}{d P}=\frac{[q(\mu)]^{2}}{q^{q}(\mu) \hat{A}(1+r)} \frac{d R}{d P}>0
\end{aligned}
$$

as it follows from the fact that $q^{q}(\mu)<0$ : As a result, a positive aggregate shock that increases the profitability of jobs increases the incentive to create new ones and thus $p(\mu)$ rises. At the same time, the shock reduces the incentive to destroy the old ones, thus ${ }^{1} G(R)$ falls. This implies that, for given dynamics of the labour force, inflows into the unemployment pool would fall while the outflow would rise.

A positive reallocative shock will increase, for a given average productivity, productivity in some firms and will reduce it in others. Intuitively, a positive reallocative shock increases the cross sectional variance of the productivity of jobs and it is equivalent to an increase in $3 / 4$ Differentiating (1) with respect to $3 / 4$ we obtain

$$
\begin{aligned}
& \frac{d J(1)}{d^{3} / 4}=\frac{9}{r+1}+{ }^{1} \frac{Z^{n}}{R} \frac{d J(y)}{d^{3} / 4} d G(y) \\
& =\frac{\eta}{r+1}+{\frac{1}{\left(r+{ }^{1}\right)\left[r+{ }^{1} G(R)\right]}}_{R}^{Z_{\eta}} y d G(y)
\end{aligned}
$$

that is positive for any $\prod_{\text {greater than zero as }}{ }_{i}^{R_{1}}{ }_{1} y d G(y)=0$ by assumption. Therefore equations (F E) and (DE) imply that

$$
\begin{aligned}
\frac{d R}{d^{3} / 4} & =\frac{(P i h)^{3 / 4}{ }^{2}}{1 i \frac{1}{r+1}[1 ; G(R)]}>0 \\
\frac{d \mu}{d^{3} / 4} & =i \frac{[q(\mu)]^{2}}{q^{q}(\mu) \hat{A}} \frac{d j(7)}{d^{3} / 4}>0
\end{aligned}
$$

In other words, an increase in $3 / 4$ leads to an increase in $\mu$ which will have a positive affect on $p(\mu)$. More jobs will be created in the high productivity sectors. At the same time more jobs will be destroyed in the low productivity ones, as $R$ increases and thus ${ }^{1} G(R)$ rises. Inflows into and outflows from the 
unemployment pool will simultaneously rise so that, ceteris paribus, worker flows should move in the same direction ${ }^{3}$. We use this result to identify an aggregate versus a reallocative shock in the context of structural VAR methodology.

One final point worth mentioning, is the distinction between worker, job and unemployment flows. In the model analysed above, they coincide exactly. This is not the case in the real world and we talk more about the empirical implications of this in section IV. Theoretically though, it is also important to draw a distinction between the various flows. Mortensen (1994) and Pissarides (1994) model on-the-job search with this in mind. More explicitly, Burda and Wyplosz (1994) model the distinction between a job and a worker-firm match. It seems that our identifying restrictions would extend to their set-up as well, once the destruction margin is modelled in the same way as in this section: on impact an aggregate (reallocative) shock will tend to move unemployment flows in opposite (same) directions ${ }^{4}$.

\section{The Structural VAR Methodology}

Let $Y_{t} ;{ }^{2}$ be two vectors containing respectively the observed values of our variables, assumed to be covariance stationary, and the structural disturbances.

From the assumption that $Y_{t}$ is a stationary process, it follows that there exists a Wold Decomposition with white noise disturbances ' $\mathrm{t}$ so that $\mathrm{Y}_{\mathrm{t}}=$

\footnotetext{
${ }^{3}$ It can also be noted that the results does not follow from the assumption that jobs are created at the upper support of the distribution of productivities. In fact the value of a job J ( 9 at any idiosyncratic productivity $9>0$ increases: implicit in a firm there is an option to stop losses when things go wrong. That is why an an increase in idiosyncratic volatility $3 / 4$ generally raises the value of a job and increases $\mu$ :

${ }^{4}$ This is not the same thing as saying that in response to an aggregate shock unemployment flows must move in opposite directions over the adjustment path. In fact, Burda and Wyplosz (1994) show that a sufficiently big adverse aggregate shock raises the unemployment stock and makes unemployment flows to move together over the adjustment path. Still, on impact, an adverse aggregate shock raise unemployment (the destruction margin raises) while the outflow rate falls.
} 
$C(L)^{\prime}{ }_{t}$ where $E\left({ }^{\prime}{ }_{t}^{\prime} g\right)=$ - If moreover we assume that the relationship between the structural disturbances ${ }^{2}$ and the observed outcomes $Y_{t}$ has a linear moving average (MA) representation, it follows that

$$
Y_{t}=C(L)^{\prime}{ }_{t}=B(L)^{2}{ }_{t} ; B(0)=B_{0} ;
$$

where $B(L)$ is a (potentially) infinite order matrix polynomial in the lag operator $L$; describing the dynamic effects on $Y_{t}$ of the structural disturbances ${ }^{2}$ : From equation (5) it follows that ${ }_{t}{ }_{t}=B_{0}{ }^{2}$ and $B_{i}=C_{i} B_{0}$, where $B_{i} ; C_{i}$ are respectively the matrix coefficients associated with the term of order $i$ in the polynomials $B(L), C(L)$ respectively.

In the analysis, we assume that the structural disturbances are uncorrelated white noise errors with unit variance. Though this is standard in the VAR literature, it is not a trivial assumption and requires some justification. A simple justification often invoked in the SVAR literature (see Blanchard and Quah 1989) is that the structural shocks, by their very nature, are fundamental shocks without a common cause and should therefore be treated as orthogonal. It certainly seems possible though, that many shocks that have impacted on the world economy in the post war period, have both aggregate and reallocative components. For example the oil price shocks of 1972 and 1979. If this is the case, the assumption of orthogonality is still tenable provided that we allow shocks to have both aggregate and reallocative components, but to consider the reallocative component to depend on the magnitude of the shock and not its direction, i.e. not whether it is a positive or negative aggregate shock. Over a long enough time period, the fundamental shocks should include a random mix of positive and negative aggregate shocks. Thus the correlation between aggregate and reallocative shocks should be zero, or close enough to zero.

This is equivalent to noting that even if the aggregate $P_{t}$ and reallocative $\S_{\mathrm{t}}$ shocks are not stochastically independent, they might still be uncorrelated. For example, suppose that the aggregate shock $\boldsymbol{P}_{\mathrm{t}}$ is symmetric and that the 
absolute size of $\S_{t}$ and $P_{t}$ are related as follows:

$$
E^{3} \S_{t} j P_{t}^{\prime}=b^{3} P_{t}^{2} i^{3 / 4}
$$

where $\mathrm{b}>0$ and $3 / 4=\mathrm{E} \quad \S_{\mathrm{t}}^{2}$ : In other words the reallocative component is related to size of the aggregate component and not its direction. Then:

$$
E^{3} \S_{t} P_{t}^{\prime}=0
$$

so that $\S_{t}$ and $P_{t}$ are uncorrelated even if not stochastically independent. If so, the orthogonality assumption is still a reasonable one.

From this, it follows that:

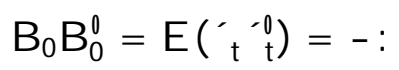

The dynamics of the coefficient $B_{i}$ represents the speed of adjustment to a given a shock. The greater the speed the faster they decay. The contribution of a shock to the underlying dynamics of a given variable is given by the contribution of the shock to the variance of the forecasting error of the variable at different leads (forecasting variance decomposition). In what follows we draw on the theoretical structure, introduced in the previous section to estimate an SVAR as in equation (5). We consider different restrictions and different vectors of variables $Y_{t}$, to identify the matrix $B_{0}$ through equation (6) and check for robustness of the results.

\section{Data Description}

The data is on: inflows to, $\mathrm{I}_{\mathrm{t}}$, and outflows from, $\mathrm{O}_{\mathrm{t}}$, unemployment, vacancies $V_{t}$, and the labour force, $L_{t}$, and is quarterly for the period 1972:3 $-1989: 4^{5}$. The countries considered are the US, the UK, France, Germany and Spain.

\footnotetext{
${ }^{5}$ The data for unemployment and the flows to and from unemployment are registry data based.
} 
Various integration and cointegration tests were performed. All variables were found to be I (1) with inflows and outflows standardized by the labour force, cointegrated with a cointegrating vector of approximately $(1 ; i 1)^{6}$. This is unsurprising, given that flows into and out of unemployment are large relative to the stock of unemployment. Thus any sharp movements in netłows should cause a sharp movement in the stock of unemployment. A pefunctory look at unemployment data for most countries, quickly shows that this rarely occurs. Also intuitively, an increase in inflows causes a rise in unemployment. Given the matching function and ceteris paribus, this should lead to an increase in matchings or outflows. See appendix A for graphs of inflows and outflows normalised by $L_{t}$.

One final point on the data should be made. In the model we analyzed in section II, unemployment, job and worker flows coincided exactly. This is not the case in the real world. The flows we have are inflows to and outflows from unemployment. These are not the same as job destruction and job creation rates. Inflows are made up of job destruction, quits into unemployment and new entrants to the labour force. Outflows are made up of job creation and exits from unemployment to out of the labour force. It is then a reasonable question to ask if the identification of aggregate and reallocative shocks in our model extend to a theoretical set-up where these distinctions are explicitly taken into account. There are good reasons to believe that it does. Burda and Wyplosz (1994) detail how for Europe at least job separations are much larger than the flow of new entrants to the labour force: the majority of workers who leave unemployment do so because they have found a job. Moreover, they highlight that quits into unemployment represent a minor component of total unemployment inflow. Further, they show that exits from unemployment to employment, in European data, are numerically larger than exits from the labour force. For example in Germany, $60-70 \%$ of outflows are attributable

\footnotetext{
${ }^{6}$ The flows to and from unemployment are likely to be measured with significant error. The strong cointegrating relationship between them could be partly due to this, though it is likely that the fact that unemployment is slow moving is far more important in explaining it.
} 
to new employment. For the US the picture is not so rosy. Clark and Summers (1979) attribute up to half the unemployment flows in the US to entry and exit from the labour force. However, for given dynamics of the labour force, on impact a reallocative (aggregate) shock will tend to move unemployment flows in the same (opposite) directions. Moreover, we also introduce additional labour force shocks, in section VI, to correct for possible discrepancies in the dynamics of jobs versus worker flows. As it will be seen later, the robustness of the main broad results might suggest that the main conclusions would have been no different if we had explicitly considered the distinction between unemployment, job and worker flows.

\section{Estimating Aggregate and Reallocative Shocks}

The considerations in section 2 suggest a very strong theoretical restriction. In response to an aggregate shock, flows into and out of the unemployment pool should move in the opposite direction, while in response to a reallocative shock, they should move in the same direction. If we write the contemporaneous effects matrix, as:

$$
\mathrm{B}_{0}=\stackrel{3 / 41}{3 / 4 b_{21}} \underset{3 / 4}{3 / 4} b_{12}^{\#} ;
$$

equation (6) imposes that the coefficient $b_{12}$ and $b_{21}$ must satisfy the following relation

$$
b_{12}=\frac{-12 i-{ }_{11} b_{21}}{-22 i-{ }_{12} b_{21}} ;
$$

while the two coefficient $3 / 4,3 / 4$ are defined as function of $b_{12}$ and $b_{21}$ only.

In what follows, we consider different restrictions on the parameters $b_{12}$ and $b_{21}$ such that (7) holds and the two coefficients are of opposite signs. $b_{12}$ and $b_{21}$ having opposite sign is a direct implication of our identification scheme for aggregate and reallocative shocks. We look at different combinations of $b_{12}$ and $b_{21}$ as a check of the robustness of our results to slight perturbations. 
As the objective of the paper is to compare across countries, we would like the variable to be scale free. (3) and (4) suggest two possible standardizations to analyze the flows: one in terms of the labour force, the other in terms of rates. Therefore and as an additional check of robustness, we consider two different two variable SVAR specifications:

2 In order to keep track of the dynamics of the unemployment rate, we consider a specification with outflows over labour force, $\frac{\mathrm{O}_{t}}{\mathrm{~L}_{t}}$; and inflows over labour force, $\frac{I_{t}}{L_{t}}$. The variables seem to be integrated of order one and cointegrated with cointegrating parameter equal to $(1,-1)$ (see the consideration of the previous section and fig1 to illustrate the cointegration relationship). Since $Y_{t}$ must be covariant stationary, the paper considers

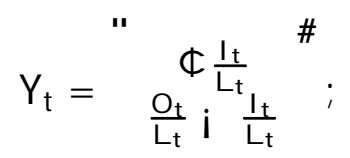

where $\phi$ indicates the first difference operator and $\frac{\mathrm{O}_{t}}{\mathrm{~L}_{t}} \mathbf{i} \frac{\mathrm{I}_{t}}{\mathrm{~L}_{t}}$ measures net flows, $\mathrm{nf}_{\mathrm{t}}$. Moreover we recover as a proxy of the impact on the unemployment rate at time $t$; the sum of the impact on $\frac{\mathrm{I}_{t}}{L_{t}} i \frac{\mathrm{O}_{t}}{L_{t}}$ :

2 Our second specification uses the outflow rate, $\frac{\mathrm{O}_{t}}{\mathrm{U}_{\mathrm{t}}}$, and the inflow rate $\frac{\mathrm{I}_{\mathrm{t}}}{\mathrm{E}_{\mathrm{t}}}$ (inflows over employment, $\mathrm{E}_{\mathrm{t}}$ ). The two variables seem to be integrated of order one and not cointegrated. Therefore, the paper considers as independent variables the vector

$$
Y_{\mathrm{t}}=\stackrel{\phi \frac{\mathrm{I}_{\mathrm{t}}}{\mathrm{E}_{\mathrm{t}}}}{\phi \frac{\mathrm{O}_{\mathrm{t}}}{\mathrm{U}_{\mathrm{t}}}}
$$

As the dynamics of the unemployment rate, $\mathrm{u}_{\mathrm{t}}$; is approximately given by $\phi u_{t}=\frac{I_{t}}{E_{t}}\left(1 ; u_{t}\right) ; \quad \frac{O_{t}}{U_{t}} u_{t}$; we also consider a measure of the forecasting variance decomposition for the changes of the unemployment rate, given by the average between the ones of inflow and outflow rate with weight equal to $\left(1 ; u_{t}\right)$ and $u_{t}$ respectively ${ }^{7}$.

\footnotetext{
${ }^{7}$ In tables 4-11 the results are obtained posing a standardizing value of $u_{t}=0: 07$ :
} 


\subsection{Identification}

In the 2 variable SVAR only one identification restriction is required to exactly identify the matrix $B_{0}$ in equation (5). In the first specification outlined above, we consider

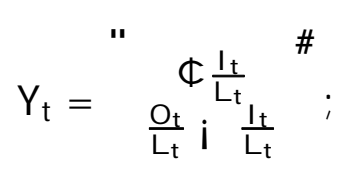

where $\frac{O_{t}}{L_{t}} i \frac{I_{t}}{L_{t}}$ measures net flows $n f_{t}$. An aggregate shock will cause $\phi \frac{L_{t}}{L_{t}}$ and $\mathrm{nf}_{\mathrm{t}}$ to move in the opposite direction, whereas a reallocative shock will cause them to move in the same direction. The logic is the one outlined in the theoretical model in section 2. Consider a positive reallocative shock that increases the productivities in some sectors and reduces it in others (an increase in the variance of the productivities of jobs $3 / 4$ ). This will cause the inflow into unemployment to rise $\left(\$ \frac{\mathrm{I}_{t}}{\mathrm{~L}_{\mathrm{t}}}\right.$ is positive) because of the contribution of declining sectors and outflows to rise, both because of the underlying trend linking the unemployment flows (cointegration) and because of the contribution of the expanding sectors. This causes outflows to increase more than what it would have done in the absence of the shock, i.e. $\mathrm{nf}_{\mathrm{t}}$ is positive. Thus $\phi \frac{I_{t}}{L_{t}}$ and $n f_{t}$ move in the same direction. An analogous argument can be applied to aggregate shocks.

We identify the SVAR by choosing combinations of $b_{12}$ and $b_{21}$ such that (7) holds and the coefficients have opposite sign. Thus we impose impact restrictions on the SVAR. We report the results for $b_{21}=1 ; 30$ and 60 to cover the range of values for which the coefficients have opposite sign ( see fig2 for the $b_{12}$; $b_{21}$ locii for all the countries for the normalization by the labour force).

For the second normalization, a similar procedure is carried out, we simply identify an aggregate shock as one which causes $\$ \frac{I_{t}}{E_{t}}$ and $\phi \frac{O_{t}}{U_{t}}$ to move in opposite direction on impact and a reallocative shock to move them in the

This value represents the approximate average of the unemployment rate of the countries considered for the sample chosen. We tried different values, choosing the average unemployment rate for each country, not across the whole sample, but found the results were virtually identical, as the weights $u_{t}$ and $1 ; u_{t}$ do not vary much. 
same direction on impact. We follow the same procedure for choosing $b_{12}$ and $b_{21}$ as above.

\section{$5.2 \quad$ Results}

The appendix gives the variance covariance decompositions, the impulse response functions and the speed of adjustment rankings for the two different two variables VAR specifications ${ }^{8}$.

Table 2 documents the impact effects, standard deviations and the long run impacts of the shocks using the standardization by the labour force. For all countries, it can be seen that the long run impact of a shock of unit standard deviation, is higher for aggregate shocks than for reallocative shocks except for Spain. This is consistent with the Variance Decomposition evidence (discussed later), that shows that aggregate shocks dominate, at least at long lags with the exception being Spain. Also the impact effects of a unit standard deviation shock are very similar for France and Germany. Spain shows higher impact effects for both shocks. Finally, it is worth noting that the size of the reallocative shocks (3/4) are much larger in Spain than in other countries.

Table 3 documents the dynamic speed of adjustment to the shocks. The entries show the values of the norm of the ranked eigenvalues of the $\operatorname{VAR}(1)$ representation of the VAR, for different specifications. In the long run, the dynamics of the system is dominated by the eigenvalue with the greatest norm. Thus, we consider this the appropriate measure to capture the long

\footnotetext{
${ }^{8}$ All the VARs in the paper were estimated with two lags. In these cases standard Durbin Watson tests performed well. We also carried out some maximum likelihood tests against specifications with longer lags. Our specification beat the one with three lags while the results were mixed for lags longer than four. In these cases however, the VARs seemed to be overparametrized as the impulse responses looked unstable. We therefore relied on the principle of parsimony by choosing the specification with the smaller number of lags. We also looked at subsample stability tests, within a country, looking at the AR estimates of each equation separately. In general, the null hypothesis that no structural break has taken place before and after the $80^{\prime} \mathrm{s}$ is not rejected. See table 1 for a test of the null hypothesis that no structural break has taken place around 1981:1.
} 
run speed of adjustment of the system ${ }^{9}$. As clearly illustrated, the US is quickest. For both our specifications, i.e. standardized by the labour force or in terms of rates, the ranking over France, Germany, the UK and Spain depends on which normalization we use. If standardized by the labour force, Germany is next, followed by France, Spain with the UK last. If we use the specification in terms of rates, the UK, Germany and Spain are quicker than France.

The US showing the quickest adjustment will not surprise many. It is often argued that the US has a more flexible labour market than the EC: with low welfare payments of a short duration, small firing costs and little trade union influence. Several authors have noted that steady state job flows are remarkably similar across the two sides of the Atlantic (OECD, 1994a, 1994b, Garibaldi et al., 1996, Alogoskoufis et al. 1995 and Bertola and Rogerson 1996). Burda and Wyplosz (1994) also note how worker flows are large in Europe and because of this they argue that European Labour markets are quite active. The results of this paper suggest, however, that European labour markets are dynamically "sclerotic", even if steady state flows might give the impression of the European labour market being quite active.

Germany being so high in the rankings may surprise a few. The apprentice system in Germany may explain the difference. In Germany, there is a comprehensive apprentice system in which firms and employees closely coordinate over the skills required and acquired by employees (see i.e. Lynch, 1994). This may allow a faster adjustment to shocks than is often perceived for Germany, given its other institutional facets like strong trade unions.

The UK may have been expected to have been second after the US in the rankings. This is certainly not the case in the normalisation by the labour force and is again repeated in the three and four variable case (see next section). The reason for this maybe that the start of the Thatcher labour

\footnotetext{
${ }^{9}$ This implies that the long run speed of adjustment of the system is independent of the specification assumed.
} 
market reforms in the UK took place in 1985. Thus for most of our sample, the UK had a fairly rigid labour market an this may explain a certain degree of ambiguity over its ranking.

Tables 4-8 show the variance decompositions of the (approximated) unemployment rate, for the two different specifications for each country. With the exception of Spain, it is found that aggregate shocks dominate, with reallocative shocks being of some importance on impact, but with diminishing influence over time.

The US results are consistent with aggregate shocks dominating. For Spain reallocative shocks dominate but more so using the labour force normalization. For France we find that aggregate shocks dominate, but with reallocative shocks having a significant effect on impact. Even at long lags, reallocative shocks explain about $40 \%$ of the movement in unemployment for France $^{10}$. Germany produces similar results to France, only that aggregate shocks dominate even more so. Again on impact, reallocative shocks have a significant influence on unemployment, but this drops to about $20 \%$ at long lags. We also note that reallocative shocks account for less in US compared to Europe. A possible explanation is that the US economy is more flexible and therefore it reallocates the labour force across jobs and sectors without causing as much unemployment, so that the contribution of reallocative shocks in forecasting unemployment is lower than that in Europe.

In Tables 9-11 we formally test the underlying hypothesis that the structures of the economies, as revealed by the impulse responses, are fundamentally different in the US and Europe. We do this by looking at the impulse responses of a country relative to those of the US and the accompanying confidence intervals. The tables are for the specification over the labour force, with results given for the different values of $b_{21}{ }^{11}$. The first number in

\footnotetext{
${ }^{10}$ It must be noted that in the normalisation by the labour force with $b_{21}=60$, we get the rather spurious that reallocative shocks dominate. We do not think this is contradicting the previous results, as the impulse responses oscillate a lot and seem very unstable for this case.

${ }^{11}$ Similar results holds for the specification in terms of rates.
} 
each box represents the difference in the impulse response of the unemployment rate of the country minus that of the US, calculated at different leads. The second number is equal to (one half) the size of the corresponding $95 \%$ confidence interval, calculated using a bootstrapping technique with 1000 replications.

Referring to Tables 9-11, it is easy to notice a well known problem with this class of tests: the standard errors are very large. Thus, the confidence intervals are correspondingly wide and it is very difficult to get statistically significant results. Nevertheless, some interesting findings do come out. The only country for which a reallocative shock is significantly different from the US, at any lead, is Spain. Further, Spain is the only country for which aggregate shocks show a significant difference at long leads. This is consistent with the view that the power of this test is very low. Thus only large differences will show up as being significantly so. We noted earlier that Spain was an exception, in that reallocative shocks dominate. The evidence presented here is consistent with this finding, in that it is the only country which shows significant differences in its responses relative to the US. On the whole, aggregate shocks show more significant differences, with all countries showing significant differences up to two quarters after a shock. France ranks after Spain, in showing the most significantly different aggregate shocks. The differences are significant up to five quarters, but thereafter remain close to significance. For both reallocative and aggregate shocks, the UK and Spain have bigger absolute differences relative to the US.

The above analysis of the tables suggests the following. Aggregate shocks dominate across countries, the important exception being Spain. There is some variation in the importance of reallocative shocks (excluding the obvious example of Spain) across countries, particularly with France showing them to have more influence when compared to Germany. The explanation for the predominance of reallocative shocks in Spain, could have been the need to reallocate workers from the agriculture to the manufacturing sectors after Franco's reign, see Marimon and Zilibotti (1996). 
Independent of the specifications, the US labour market is quicker to adjust than European economies. There is also a ranking inside European economies with Germany quicker than other EEC partners even if still slower than the US.

\section{Labour Force Shocks}

The two variable VAR specifications above, have given us some interesting results. In order to investigate if the results are driven by the particular specifications chosen, we augment them by considering in more detail the labour force.

Firstly, we show how the theoretical set-up can account for labour force shocks. These can be of two types, either affecting the size or the composition of the labour force. We then draw on these theoretical considerations to identify a skill unbiased labour force shock which represents changes in the size of the labour force alone, and a skill biased shock that deals with the compositional change alone.

\subsection{Theoretical Labour Force considerations}

In the real world, workers can be in one of three states: working in a firm, unemployed or out of the labour force. Unemployed workers can either be actively searching or stop searching and go out of the labour force. There are in fact vast movements in and out of the labour force which we hope to capture better by explicitly using the labour force as a variable.

The reallocative and aggregate shocks considered previously are shocks directly affecting the firm. To complete the model, we must consider shocks that directly affect the labour force. These can be of two types, either affecting the size or the composition of the labour force. Thus we consider two further shocks which characterise these two effects separately. The skill unbiased labour force shock represents changes in the size of the labour force alone, and the skill biased shock deals with the compositional change alone. 
In the model outlined in section two, no shock had a permanent effect on the unemployment rate. This is, however, the result of the particular model specification chosen there. For example, Acemoglu (1996) shows that once the choice of technology is made endogenous and firms freely choose their optimal levels of capital, multiple equilibria can arise in the basic model. If so, change in the aggregate conditions (change in $\mathrm{P}$ and $3 / 4$ ) can shift the economy from one equilibrium to the other. However, if the matching function has constant returns to scale, changes in the size of the labour force $L_{t}$ alone, represent just a change in the scale of the economy. Given the assumption that no job can exploit economies of scale, $L_{t}$ can never have long run effects on the level of unemployment. In fact, there is a large body of evidence, across countries, that suggests that the unemployment rate is untrended in the long run despite huge increases in the size of the labour force. Moreover, economies with very different labour force sizes have very similar unemployment rates (see i.e. Layard, Nickell and Jackman 1991).

We therefore identify the skill unbiased labour force shock by imposing that it has no long run effect on the unemployment rate. This shock is introduced for two reasons: firstly because it allows us to evaluate if labour force influences affect unemployment dynamics in the short run; and secondly because it might correct for possible discrepancies in the dynamics of jobs versus worker flows. It gauges what is the short run contribution of structural shocks that do not exhibit permanent effects on the level of the unemployment rate.

Even if changes in the size of the labour force do not a have long run impact on the level of the unemployment rate, changes in the composition of the labour force might. Acemoglu $(1997,1998)$ shows that firms can react to changes in the composition of the labour force, by 'directing' technological change towards specific skills. More specifically, when the composition of the labour force changes, the nature of the equilibrium might change, with firms starting to create separate jobs for the skilled and unskilled.

To consider the effects of a skill biased technological shock, we modify the 
model in section 2 as follows. We assume that each worker is endowed with a given amount of skill $\mathrm{x}$ : The skill $\mathrm{x}$ is worker specific and can be transferred from one job to the other. We indicate with $F(\varnothing$ the distribution function of skills $\mathrm{X}$ in the labour force. The productivity of the job, once it is operated by a worker with skill $x$, is given by the sum of three components $P+3 / 4 \mid+$, $\mid x$ : $\mathrm{P}, 3 / 4$ and , are common to all jobs, while $\mathbb{\eta}$ is an idiosyncratic component of productivity that, as before, evolves according to a Poisson process with rate of arrival ${ }^{1}$ : The third component is new. It captures mismatch. In a Walrasian economy with no frictions, high productivity workers (high $\mathrm{x}$ ) should be matched with high productivity firms, (high 9 : In a market with search frictions this is not always the case and high productivity workers can be operating jobs hit by a negative idiosyncratic shock. , measures then the size of skill mismatch. When, is equal to zero, there is no skill mismatch and the allocation of worker-skills to jobs has no effect on productivity. When, is high the social cost of allocating 'good' workers to 'bad' jobs is high. A change in, is a skill biased labour force shock, for example an increase in , corresponds to an increase in skill mismatch: the social cost of misallocating skills increases.

Given these additional assumptions equations (DE) and (2) becomes equal to

$$
P+3 / R+, R x=h i \frac{1(3 / 4+, x)}{r+1}{ }_{R}^{Z}[1 ; G(y)] d y \quad \text { (DE') }
$$

so that 81 > R

$$
J(q x)=(3 / 4+, x) \frac{\left(q_{i} R\right)}{1+r}
$$

while $\mathbf{J}(\boldsymbol{q} \mathbf{x})=0$ if $\mathbb{q} \quad R$ where now both the asset value of a job and the reservation productivity depends on $x$. Differentiating (DE') and (8) with respect to, and $3 / 4$ we then obtain that

$$
\begin{aligned}
\frac{d R}{d,} & =\frac{n x(P ; h)}{(3 / 4+, x) 1 ; \frac{1}{r+1}[1 ; G(R)]} 0=x \frac{d R}{d^{3} / 4} \\
\frac{d J(q ; x)}{d,} & =\frac{x(\eta ; R) i(3 / 4+, x) \frac{d R}{d}}{1+r}
\end{aligned}
$$


and

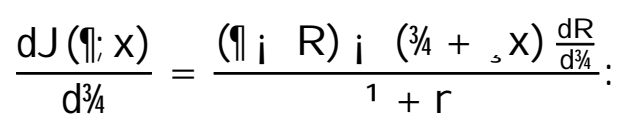

Therefore the three equation together implies that

$$
\frac{d J(q x)}{d,}: \frac{d R}{d,}=\frac{\left(\prod_{j} R\right)}{(1+r) \frac{d R}{d^{3} / 4}} ; \frac{(3 / 4+, x)}{(1+r)}=\frac{d J(\Re ; x)}{d^{3} / 4}: \frac{d R}{d^{3} / 4}:
$$

That is the relative impact of a skill biased labour force shock (change in, ) on the destruction margin $\mathrm{R}$ and on the overall profitability of the job $\mathrm{J}(\boldsymbol{q} ; \mathrm{x})$ is equal to that of a reallocative shock (change in $3 / 4$ :

(9) suggests a possible way of identifying a skill biased labour force shock: for given size of the labour force, a skill biased labour force shock has similar effects on unemployment flows when compared to a reallocative shock. This symmetry is appealing as skill mismatch and reallocative shocks are really compositional effects, the former being on the labour force side, the latter being on the firm side.

\subsection{Augmented VARs}

Given the labour force considerations documented above, we consider extending our empirical evaluation by augmenting our previous VAR analysis. We do this by adding variables to the VARs, to capture labour force size and skill effects. We include the total labour force and the stock of vacancies to achieve this. Vacancies is an important addition, as it captures the firm-side demand. In particular, if the work force has a lower average level of skill, then firms may put out less vacancies, as the potential profit stream from a job will have fallen (Pissarides 1992). This illustrates how introducing vacancies as an additional variable may capture skill compositional changes better.

We first consider a three variable SVAR with

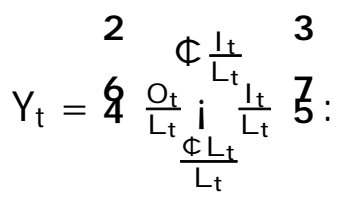


Each of the variables in $Y_{t}$ is found to be stationary according to preliminary statistical investigation.

This specification allows one to recover, perfectly, the unemployment rate $\mathrm{u}_{\mathrm{t}}$ as

$$
\Phi u_{t}=\frac{I_{t}}{L_{t}} ; \frac{O_{t}}{L_{t}} ; \frac{\Phi L_{t}}{L_{t}} u_{t}
$$

once a standardizing value for $\mathrm{u}_{\mathrm{t}}$ is chosen ${ }^{12}$.

We have argued in section 6.1 above, that there are two elements to labour force changes: a size effect and a compositional effect reflecting the skill make up of the labour force. To capture both these effects we estimate a four variable SVAR with

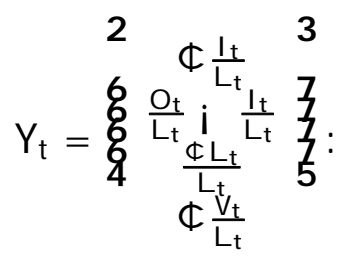

$V_{t}$ represents vacancies at time $t$. Vacancies standardized by the labour force, $\frac{V_{t}}{L_{t}}$, were found to be I (1) and so were entered in differences in the SVAR. The effects on the unemployment rate are recovered as in the three variable case above.

\subsection{Identification}

For the three variable SVAR three independent identification restrictions are required to exactly identify the matrix $B_{0}$ in equation (5). We identify the reallocative and aggregate shocks by imposing that the relative impact of both a reallocative and an aggregate shock on inflows $\phi \frac{I_{t}}{L_{t}}$ and on net flows, $\mathrm{nf}_{\mathrm{t}}=\frac{\mathrm{O}_{\mathrm{t}}}{\mathrm{L}_{\mathrm{t}}} \mathrm{i} \frac{\mathrm{I}_{\mathrm{t}}}{\mathrm{L}_{\mathrm{t}}}$; in the three variable case is equal to that of the two variable case. We believe this to be a reasonable procedure, because we are using the 3 and 4 variable SVARS firstly to check the robustness of the 2 variable

\footnotetext{
${ }^{12}$ In the table 12 the results are obtained posing a value of $u_{t}=0: 07$ : Changing this standardized value does not change the results, as the size of $\frac{\Phi L_{t}}{L_{t}}$ is small with respect to that of unemployment flows.
} 
SVAR results and secondly to isolate labour force influences in the dynamics of the unemployment rate. We draw on the considerations in section 6.1 to identify the third shock and we impose that it has no long run effect on the level of the unemployment rate. We call this a skill unbiased labour force shock, its role is to correct for the behavior of inflow and outflows that can be driven by changes in the labour force rather than changes in the creation and destruction of jobs. Evidence across many countries suggests that the unemployment rate is unrelated to that of the labor force over long horizons (see i.e. Layard, Nickell and Jackman 1991). This shock gauges what is the short run contribution of structural shocks that do not exhibit permanent effects on the level of the unemployment rate.

For the four variable SVAR, six independent identification restrictions are required. We use the three given above and hence require three more. We identify the fourth shock, the skill biased labour force shock, by imposing that its relative impact on inflows $\phi \frac{I_{t}}{L_{t}}$ and on net flows, $n f_{t}=\frac{O_{t}}{L_{t}} i \frac{I_{t}}{L_{t}}$; is equal to that of a reallocative shock. The justification draws on equation (9): reallocative shocks and skill biased shocks are really both compositional effects, the former being on the firm side and the latter being on labour force side. Both shocks are really about mismatch and therefore we would expect similar effects on inflows and outflows. Moreover we impose that a skill biased shock has no effect on the size of the labour force on impact. This is simply an orthogonalization, to separate out the size and compositional effects of a labour force change. The third required identifying restriction is delivered directly by the assumption that a skill unbiased labour force shock has no long run impact on the unemployment. This implies that it can not have a long run effect on the level of vacancies standardized by the labour force as well.

\subsection{Results}

Tables 12 and 13 show how the results from the basic, two variables, VARs extend to this case as well. The relative weight of aggregate versus realloca- 
tive shocks is unchanged in the variance decomposition of the unemployment rate, as is the speed of adjustment ranking ${ }^{13}$. In particular we do not find that the speed of adjustment ranking is affected by taking into account explicitly for the dynamics of the labour force. Moreover the role of the skill unbiased labour force shock on the variance covariance decomposition of the unemployment is very small, so that most of its dynamics is driven by shocks that have permanent effects. One interesting result to notice is the difference in the importance of the skill biased shock between France and Germany. In France it has more influence on the variance decomposition of unemployment than for Germany (approx 25\% in France as opposed to $5 \%$ in Germany at long lags). This is consistent with the two variable SVAR results where reallocative shocks were more important in France than in Germany. The importance of the skill biased shock in France suggests that skill biased technical progress might explain more unemployment in France than other OECD countries, particularly when comparing with Germany. In Germany the apprentice system may allow it to absorb these kind of shocks better.

\section{Conclusions}

The European Community and the US have experienced vastly different unemployment dynamics over the last two decades. This paper has investigated whether these differences are due to exposure to different shocks or reacting differently to the same shocks. With the premise of a search theoretic framework and a structural VAR methodology, the paper has robustly identified aggregate versus reallocative shocks. With the exception of Spain where most of the dynamics seems to be driven by reallocation, it is found that most differences in unemployment dynamics arise because of differences in responses

\footnotetext{
${ }^{13}$ There are slight exceptions here. The three variable results for Spain suggest that aggregate shocks dominate. This goes against the results fo the two and four variable cases. We believe the result does not contradict the previous ones for the same reasons that were suggested for France in the two variable case with $b_{21}=60$, namely that the impulse response functions oscillate a lot and seem very unstable for this case. Also in the four variable VAR, France has a higher speed of adjustment than Germany.
} 
to shocks. In particular European economies seem to respond slower to the same shock, when compared with the US. This implies that EEC economies might be dynamically "sclerotic" even if the size of the steady state job flows might give the impression of the European labour market being quite active.

In order to check for robustness we have introduced additional labour force shocks identified, respectively, as a skill unbiased and a skill biased component. We have shown that skill unbiased labour force shocks do not appear to have much influence for any of the countries considered, so that most structural shocks exhibit permanent effects on the level of the unemployment rate. The skill biased component seems to be relevant in accounting for unemployment dynamics. This implies that skill biased technological progress might explain some of the unemployment problems of OECD economies. 


\section{Appendix A - Data Sources}

The French data came from the Ministere du Travial, the German data from the Bundesanstalt fur Arbeit, the Spanish data from the Bank of Spain, the UK data from the Employment Gazette and the US data from the Employment and Earnings survey.

The data are quarterly and refers to the period 1972:3 -1989:4. For a more detailed description of the data see Burda and Wyplosz (1994). 


\section{References}

[1] Acemoglu, D., (1996) "A Microfoundation for Social Increasing Returns in Human Capital Accumulation", Q uarterly J ournal of E conomics, 1113, August, 779-804.

[2] Acemoglu, D., (1997) "Changes in Unemployment and Wage Inequality: an Alternative Theory and some Evidence", Mimeo Department of Economics, MIT.

[3] Acemoglu, D., (1998) "Why do New Technologies Complement Skills? Directed Technical Change and Wage Inequality", forthcoming Quarterly J ournal of Economics.

[4] Alogoskoufis, G., C. Bean, G. Bertola, D. Cohen, J. Dolado and G. SaintPaul (1995), "Unemployment: What Choice for Europe?", Monitoring European Integration, 5, C.E.P.R. London.

[5] Bean, C., (1994), "European Unemployment: a Survey", J ournal of Economic Literature,Vol. 32, June, 573-619.

[6] Bentolila, S. and Bertola, G., (1990), "Firing Costs and Labour Demand: How Bad is Eurosclerosis?", Review of Economic Studies, 57, 381-402.

[7] Bernanke, B., (1986), "Alternative Explanations of the Money-Income Correlation", Carnegi e-Rochester Conference Series on Public Policy 25, 49-100.

[8] Bertola, G. and Rogerson R. (1997), "Institutions and Labor Reallocation", European E conomic Review, 41-6 June, 1147-1172.

[9] Blanchard, O.J. and Summers, L., (1986) "Hysteresys and the European unemployment problem", NBER Macroeconomics A nnual 1, 15-78, Stanley Fischer (editor), MIT press.

[10] Blanchard, O.J. and Diamond P. (1989), "The Beveridge Curve", B rookings Papers on E conomic Activity 1989, 1, 1-60.

[11] Blanchard, O.J. and Quah D. (1989), "The Dynamic Effects of Aggregate Demand and Supply Disturbances", American Economic Review, $79,655-673$. 
[12] Blanchard, O.J. and Diamond P. (1989), "The Beveridge Curve", B rookings Papers on E conomic Activity 1990, 2, 85-155.

[13] Blanchard, O.J. and Diamond P. (1990), "The Cyclical Behaviour of Gross Flows of Workers in the United States", Brookings Papers on Economic Activity, 1, 1-76.

[14] Blanchard, O.J. and Diamond P. (1992), "The Flow Approach to Labor Markets", American Economic Review, 82, May, 354-359.

[15] Blanchard, O.J. and Katz L. (1996), "What we Know and We do not Know about the Natural Rate of Unemployment?", NBER Working Paper Seriesno. 5822, November.

[16] Burda, M. and Wyplosz C. (1994), "Gross Worker and Job Flows in Europe", European E conomic Review, 38(6), June, 1287-1315.

[17] Caballero, R. and M. Hammour, (1996), "On the Timing and Efficiency of Creative Destruction", Quarterly J ournal of E conomics, 805-851.

[18] Caballero, R. and M. Hammour, (1994b), "The Cleansing Effect of Recessions", American E conomic Review Vol. 84 NO.5, December, 13501368 .

[19] Clark, K. and Summers, L. (1979), "Labor Market Dynamics and Unemployment: a Reconsideration", Brookings Papers on Economic Activity 1990, 1, 13-60.

[20] Davis, S. and J. Haltiwanger, (1990), "Gross Job Creation and Destruction: Microeconomic Evidence and Macroeconomics Implications", NBER Macroeconomics Annual , 5, 99-113.

[21] Davis, S. and J. Haltiwanger, (1992), "Gross Job Creation, Gross Job Destruction and Employment Reallocation", Quarterly J ournal of E conomics 107, 819-63.

[22] Davis, S. and J. Haltiwanger, (1994), "Driving Forces and Employment Fluctuations: New Evidence and Alternative Interpretations", Mimeo, University of Maryland.

[23] Dolado,J.J. and Jimeno J. F. (1997), "The Causes of Spanish Unemployment: A Structural VAR Approach", European Economic Review, 41-7, July, 1281-1308. 
[24] Gali, J. and M. Hammour, (1991), "Long Run Effects of Business Cycles", Mimeo, (Columbia University, New York).

[25] Garibaldi P., Konings, J. and Pissarides C. (1996), "Gross Job Reallocation and Labour Market Policy" in Unemployment Policy: Government Options for the Labour Market, edited by Snower, D. and De la Dehesa G., C.E.P.R., London.

[26] Hosios, A. (1991), "Unemployment and Vacancies with Sectoral Shifts", American Economic Review, 84-1, March, 78-98.

[27] Juhn C., Murphy K. and Pierce B. (1993), "Wage Inequality and the Rise in the Returns to Skill", J ournal of Political E conomy, 101-3, 410442.

[28] Katz L. and Murphy K. (1992), "Changes in Relative Wages, 19631987: Supply and Demand Factors", Quarterly J ournal of E conomics, February, 35-78.

[29] Jackman, R., Layard,R. and Pissarides, C. (1989), "On Vacancies", Oxford Bulletin of Economics and Statistics, 51, November, 377-95.

[30] Jovanovic, B. (1979), "Job Matching and the Theory of Turnover", J ournal of Political Economy, 87, 972-990.

[31] Jovanovic, B. (1984), "Matching, Turnover and Unemployment", J ournal of Political Economy, 92, 108-122.

[32] Layard R., Nickell S. and Jackman R. (1991), Unemployment: Macroeconomic Performance and the Labour Market, Oxford University Press.

[33] Lilien, D. (1982), "Sectoral Shifts and Cyclical Unemployment", J ournal of Political Economy, 90, 777-793.

[34] Lindbeck,A., and Snower D.J. (1988), The Insider-O utsider Theory of Employment and Unemployment, Cambridge: MIT Press.

[35] Lynch, L. (1994), Training and the Private Sector: International Comparisons, National Bureau of Economic Research Comparative Labor Market Series, University of Chicago Press.

[36] Marinon, R. and Zilibotti, F. (1996), "Actual versus Virtual employment in Europe: is Spain different?", European Economic Review, 42-1, January, 123-53. 
[37] Mortensen, D.T., (1994), "The Cyclical Behaviour of Job and Worker Flows", J ournal of Economic Dynamics and Control, 18, July, 11211142.

[38] Mortensen, D.T. and C. Pissarides,. (1994), "Job Creation and Job Destruction in the Theory of Unemployment" Review of E conomic Studies, 61, July, 397-415.

[39] Mortensen, D.T. and C. Pissarides,(1998), "Technological Progress, Job Creation and Job Destruction", Review of Economic Dynamics, 1-4, October, 733-753.

[40] OECD (1994a), Employment Outlook 1994, OECD, Paris.

[41] OECD (1994b), The OECD J ob Studies, OECD, Paris

[42] Pissarides, C. A., (1986), "Unemployment and Vacancies in Britain", Economic Policy, 3, 499-559.

[43] Pissarides, C. A., (1990), Equilibrium Unemployment Theory, Oxford: Basil Blackwell 1990.

[44] Pissarides, C. A., (1992), "Loss of Skill during Unemployment and the Persistence of Employment Shocks", Quarterly J ournal of Economics, 107-4, November, 1371-1391.

[45] Pissarides, C. A., (1994), "Search Unemployment with On-the-job Search", Review of Economic Studies, 61, July, 457-475. 


\section{Inflows into and Outflows from the Unemployment Pool}
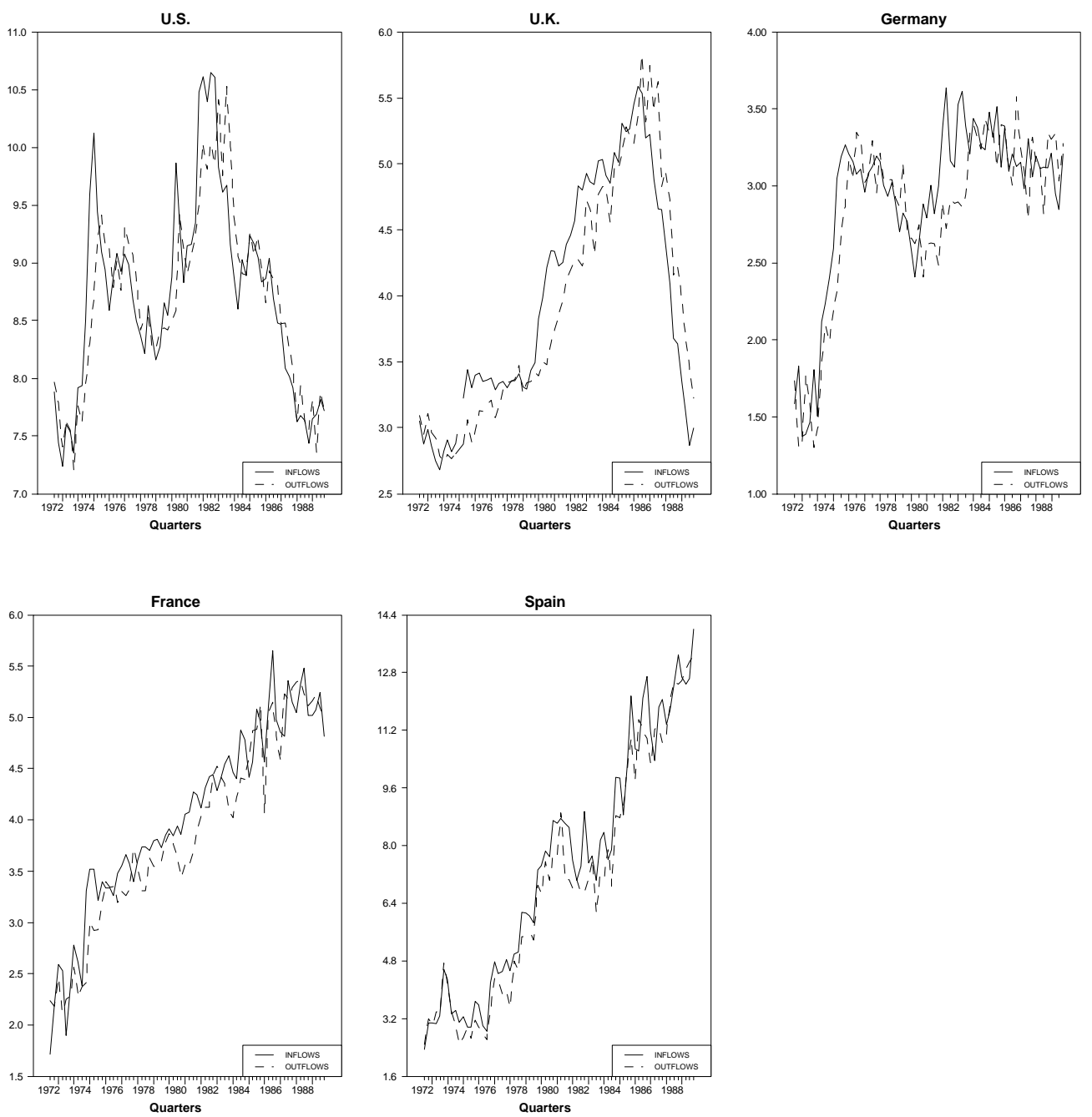

Figure 1: The graphs show the dynamics for the level of the inflows into, $\frac{\mathrm{I}_{t}}{\mathrm{~L}_{\mathrm{t}}}$; and the outflows from the unemployment pool, $\frac{\mathrm{O}_{t}}{\mathrm{~L}_{t}}$; standardized by the labour force. The data are quartely and refer to the period 1972:3 -1989:4. 


\section{Range for Parameter Values (b12 vs. b21)}
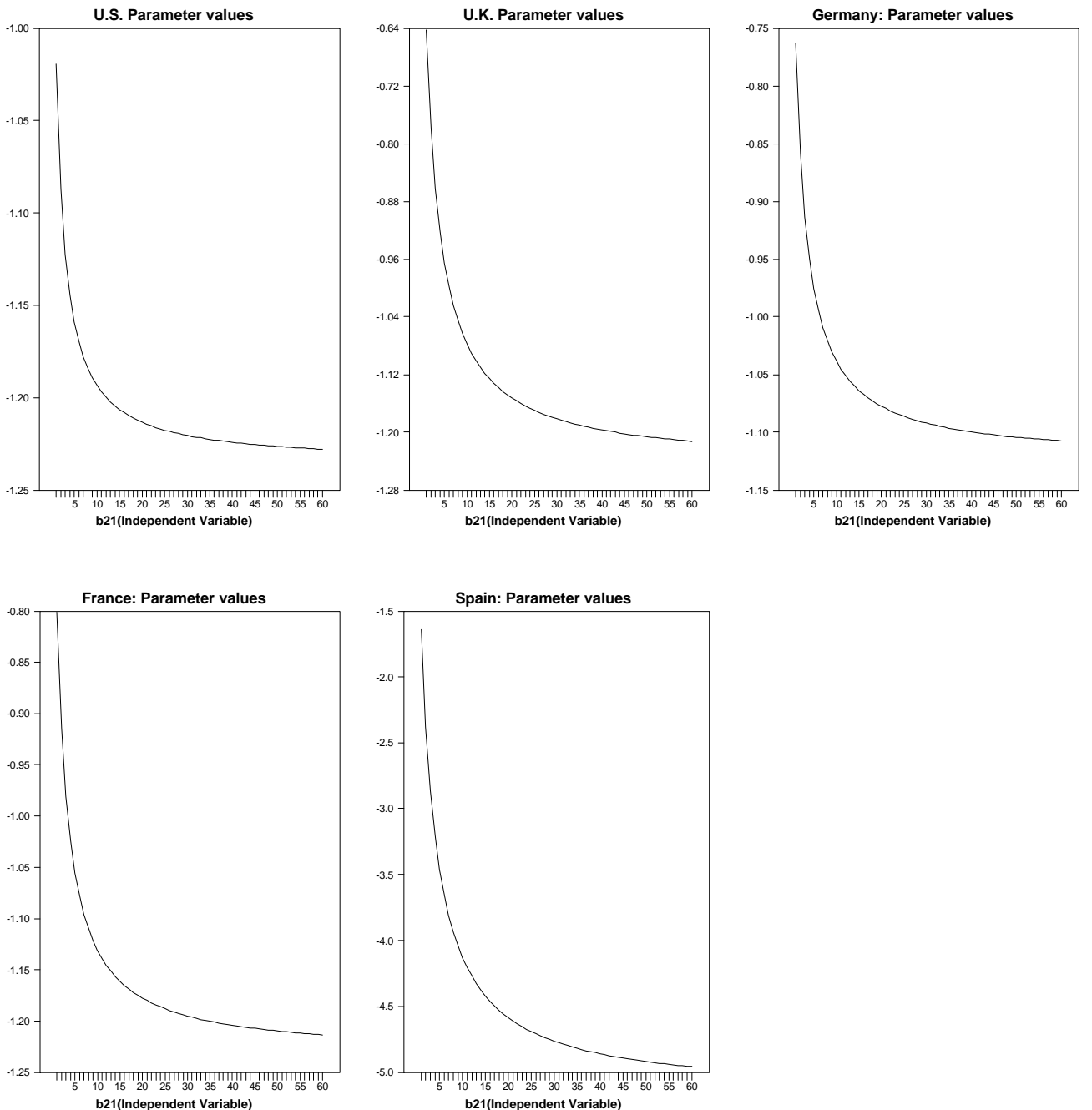

Figure 2: The graphs show the relation between $b_{12}$ and $b_{21}$ as given by equation (7) in the main text, for the two variables specification with $\frac{\mathrm{O}_{t}}{\mathrm{~L}_{t}} \mathbf{i} \frac{\mathrm{I}_{t}}{\mathrm{~L}_{t}}$ and $\frac{I_{t}}{L_{t}}$ as independent variables. 


\section{U.S.: Impulse Responses, 2 Variables VAR}
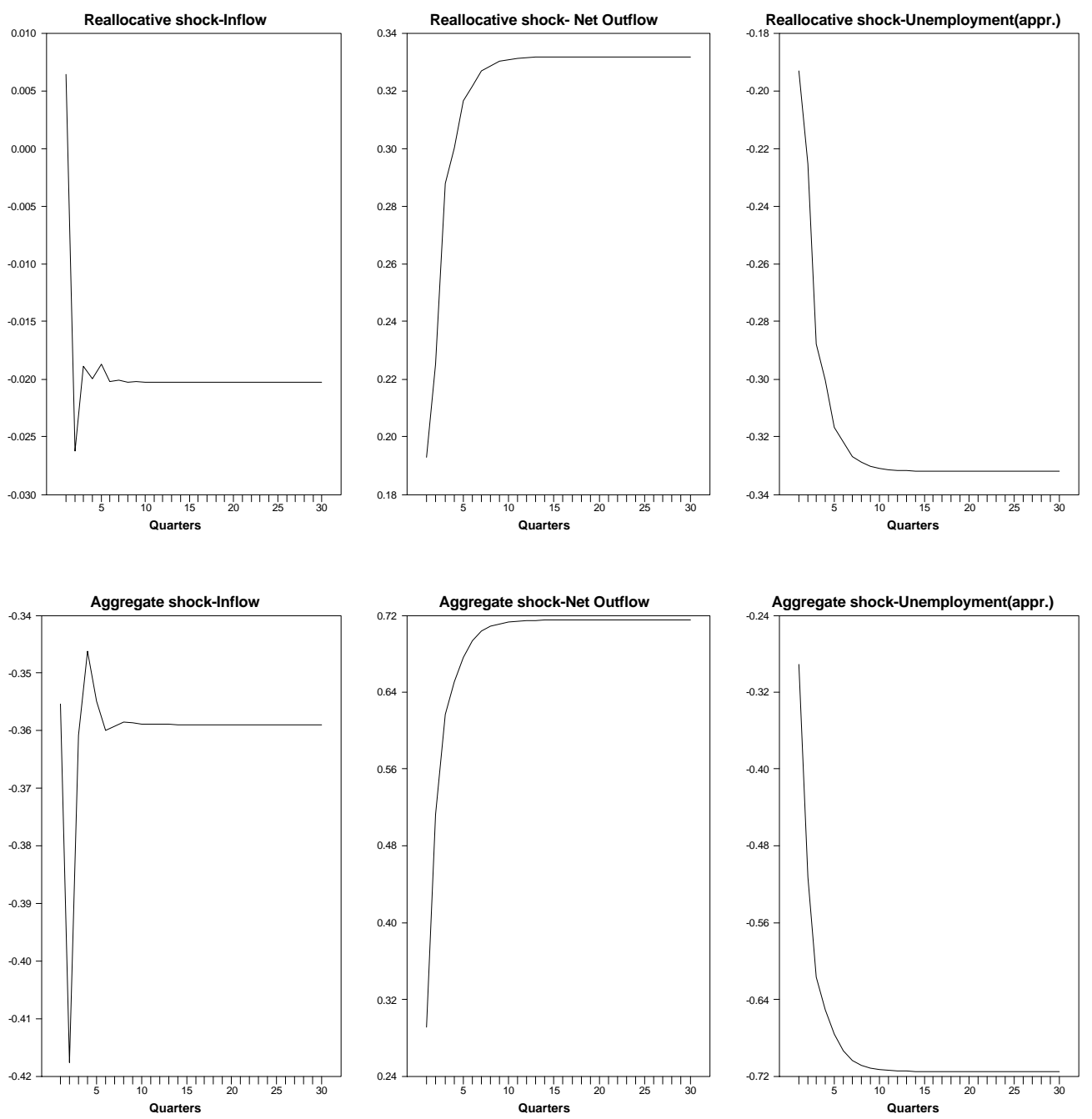

Figure 3: Impulse responses for $\frac{\mathrm{I}_{t}}{\mathrm{~L}_{t}}$ and $\frac{\mathrm{O}_{t}}{\mathrm{~L}_{t}} \mathrm{i} \frac{\mathrm{I}_{t}}{\mathrm{~L}_{t}}$ using a V AR with two lags. The response for the (approximated) unemployment rate is obtained as the cumulated response of $\frac{\mathrm{I}_{t}}{\mathrm{~L}_{\mathrm{t}}} i \frac{\mathrm{O}_{t}}{\mathrm{~L}_{\mathrm{t}}}$. The coefficient $\mathrm{b}_{21}$ is chosen to be equal to 30 . 


\section{U.K.: Impulse Responses, 2 Variables VAR}
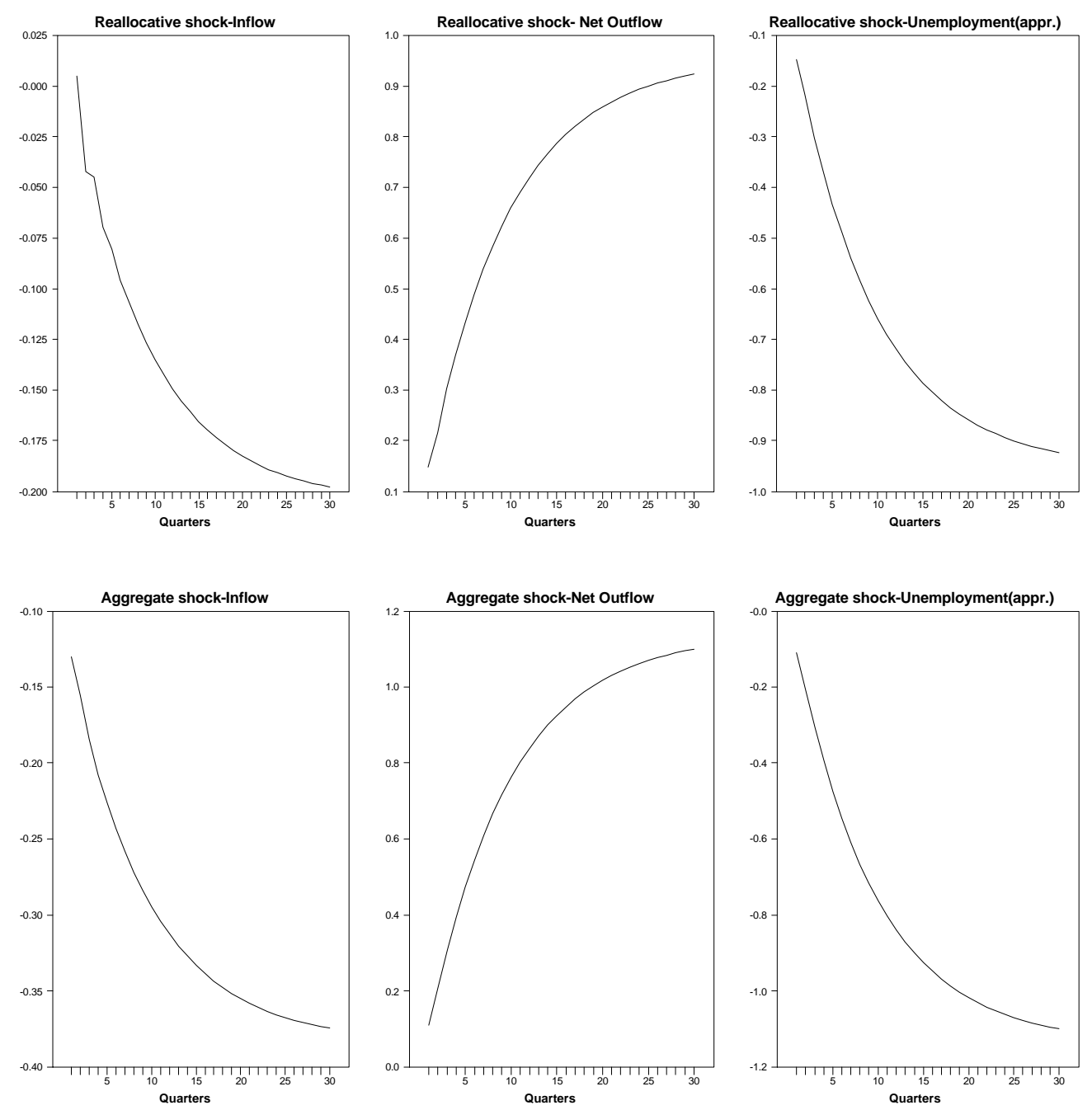

Figure 4: Impulse responses for $\frac{\mathrm{I}_{t}}{L_{t}}$ and $\frac{\mathrm{O}_{t}}{L_{t}} \mathrm{i} \frac{\mathrm{I}_{t}}{L_{t}}$ using a V AR with two lags. The response for the (approximated) unemployment rate is obtained as the cumulated response of $\frac{\mathrm{L}_{t}}{\mathrm{~L}_{\mathrm{t}}} \mathrm{i} \frac{\mathrm{O}_{t}}{\mathrm{~L}_{t}}$ : The coefficient $\mathrm{b}_{21}$ is chosen to be equal to 30 . 


\section{FRANCE: Impulse Responses, 2 Variables VAR}
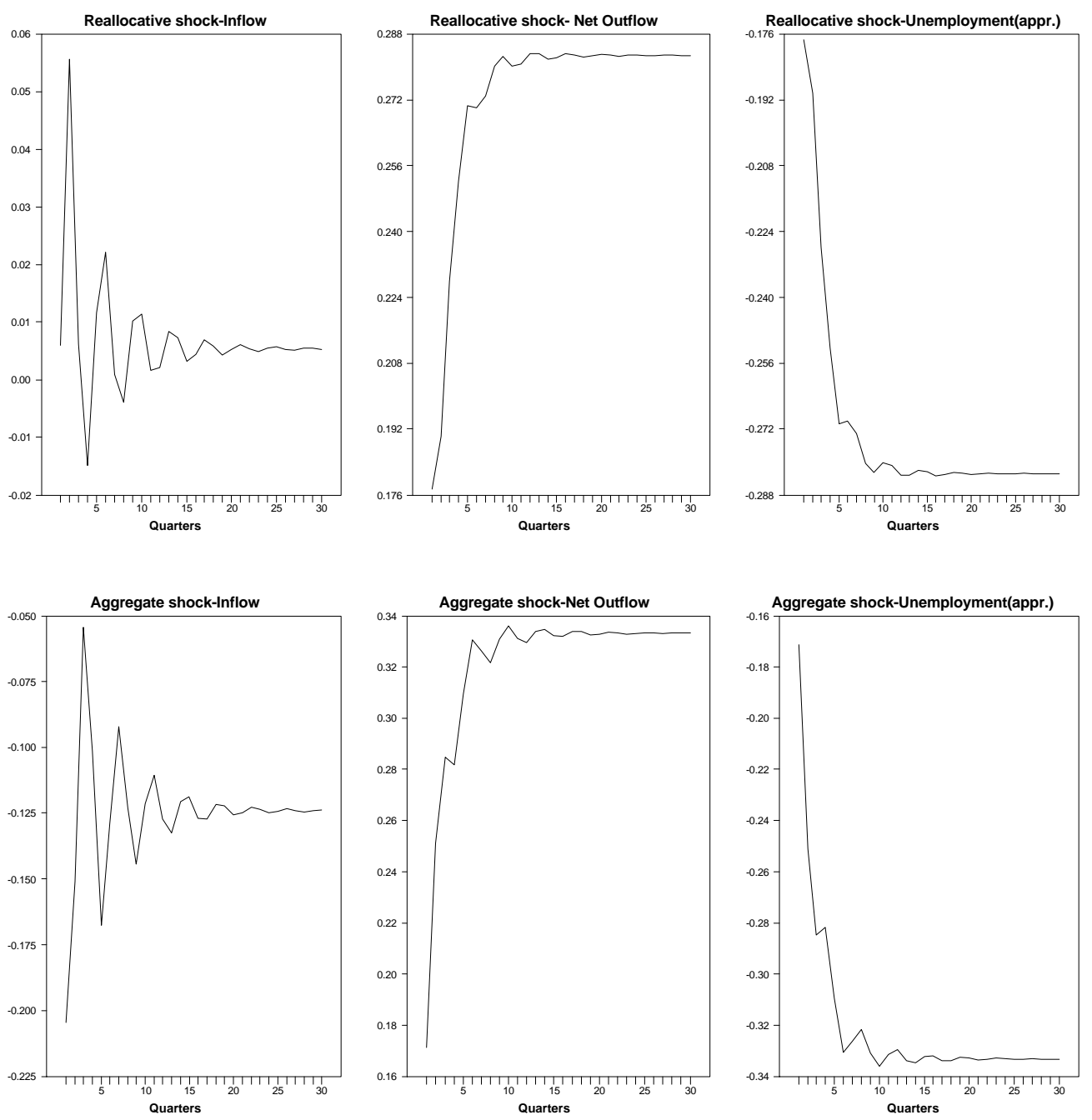

Figure 5: Impulse responses for $\frac{I_{t}}{L_{t}}$ and $\frac{\mathrm{O}_{t}}{L_{t}} \mathrm{i} \frac{\mathrm{I}_{t}}{\mathrm{~L}_{t}}$ using a V AR with two lags. The response for the (approximated) unemployment rate is obtained as the cumulated response of $\frac{I_{t}}{L_{t}} i \frac{O_{t}}{L_{t}}$ : The coefficient $b_{21}$ is chosen to be equal to 30 . 


\section{GERMANY: Impulse Responses, 2 Variables VAR}
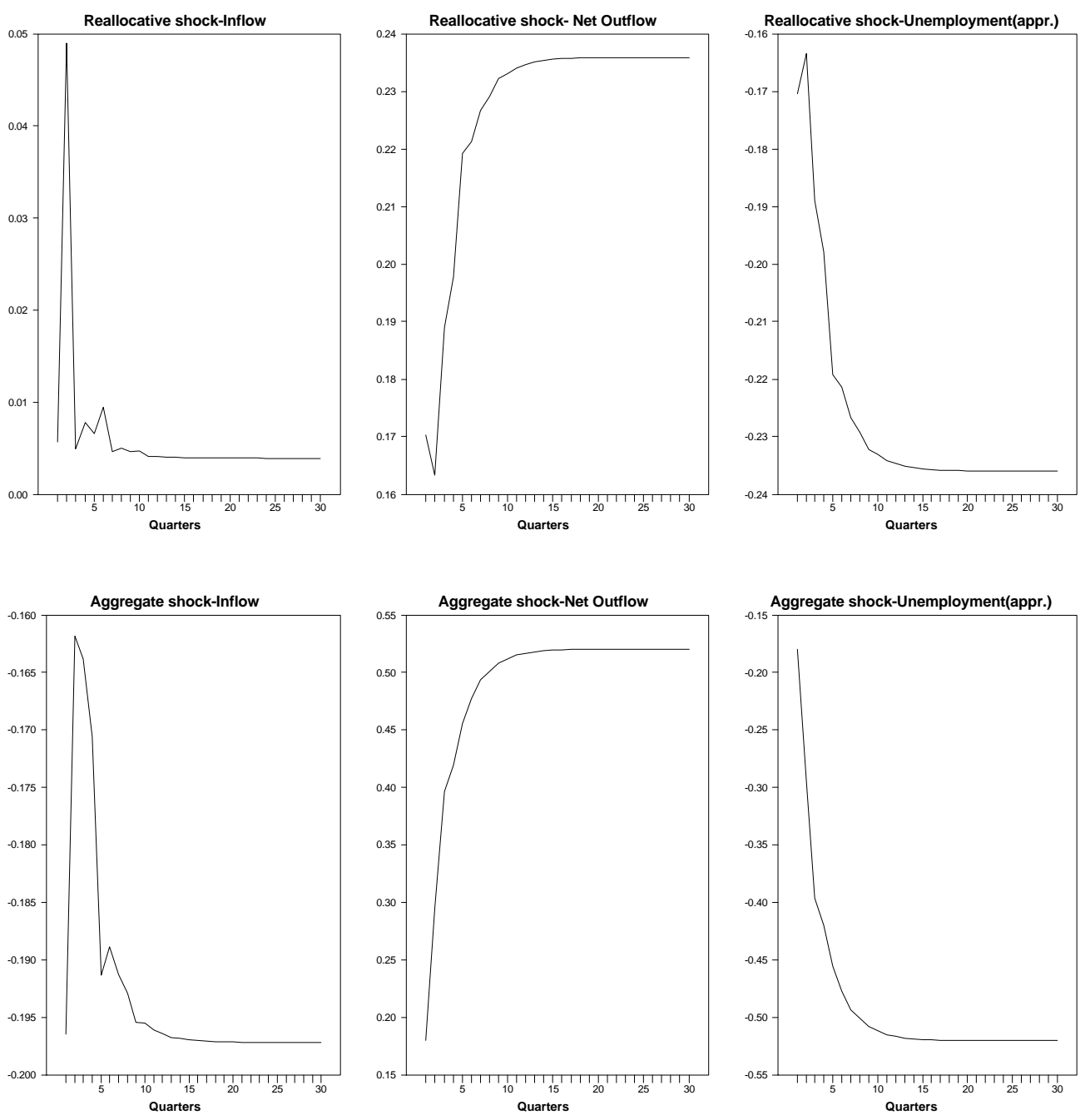

Figure 6: Impulse responses for $\frac{I_{t}}{L_{t}}$ and $\frac{\mathrm{O}_{t}}{L_{t}} \mathrm{i} \frac{\mathrm{I}_{t}}{\mathrm{~L}_{t}}$ using a V AR with two lags. The response for the (approximated) unemployment rate is obtained as the cumulated response of $\frac{I_{t}}{L_{t}} i \frac{O_{t}}{L_{t}}$ : The coefficient $b_{21}$ is chosen to be equal to 30 . 


\section{SPAIN: Impulse Responses, 2 Variables VAR}
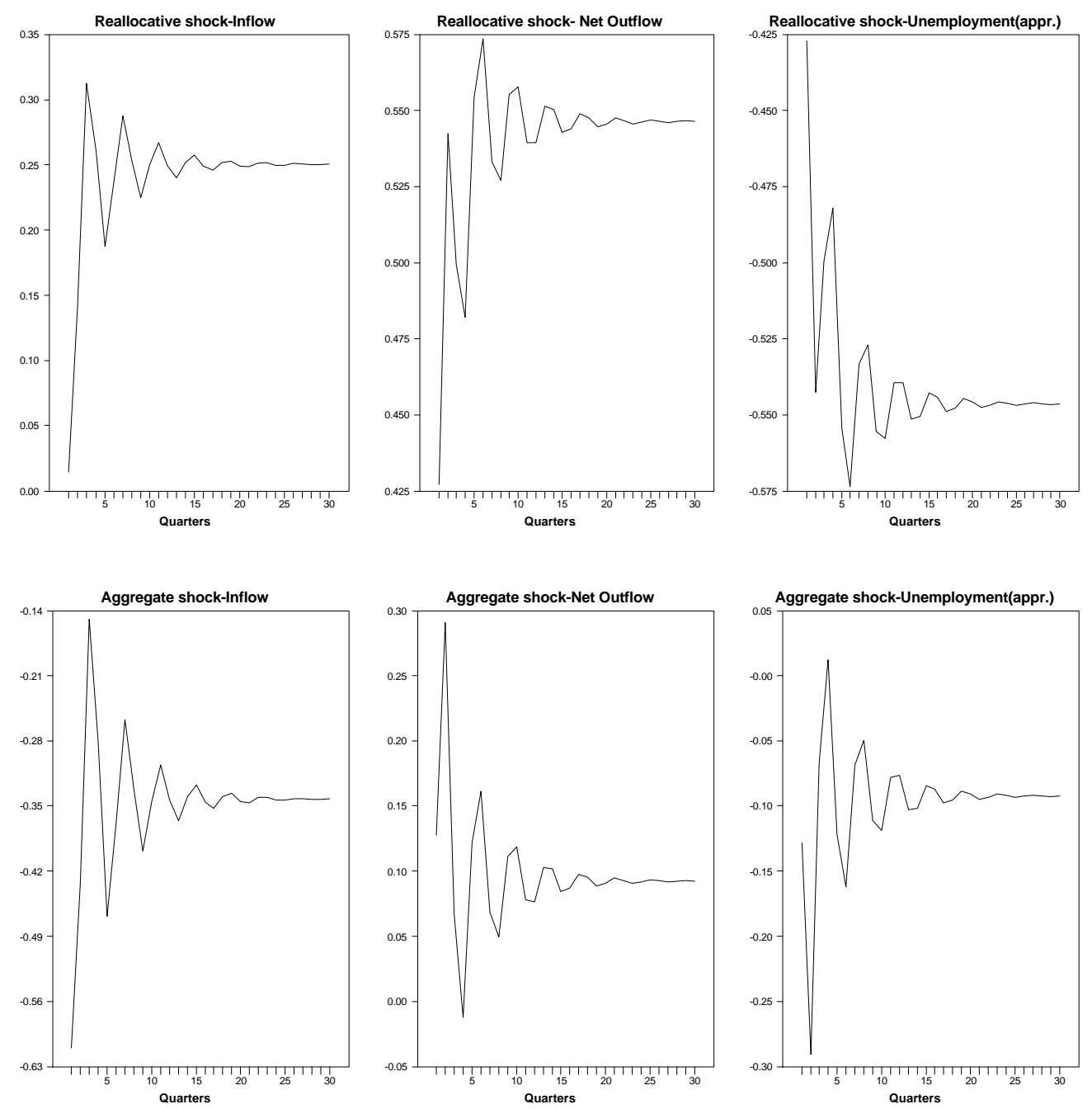

Figure 7: Impulse responses for $\frac{I_{t}}{L_{t}}$ and $\frac{O_{t}}{L_{t}} \mathrm{i} \frac{I_{t}}{L_{t}}$ using a V AR with two lags. The response for the (approximated) unemployment rate is obtained as the cumulated response of $\frac{\mathrm{I}_{t}}{\mathrm{~L}_{t}} i \frac{\mathrm{O}_{t}}{\mathrm{~L}_{t}}$ : The coefficient $\mathrm{b}_{21}$ is chosen to be equal to 30 . 


\begin{tabular}{|l|c|c|c|c|}
\hline \multirow{2}{*}{ Countries } & \multicolumn{4}{|l|}{ Equations: } \\
\cline { 2 - 5 } & $\frac{\mathrm{O}}{\mathrm{L}} \mathbf{i} \frac{1}{\mathrm{~L}}$ & $\frac{1}{\mathrm{~L}}$ & $\frac{\mathrm{O}}{\mathrm{U}}$ & $\frac{1}{\mathrm{~N}}$ \\
\hline US & .75 & .74 & .89 & .54 \\
\hline UK & .49 & .58 & .22 & .19 \\
\hline Spain & .26 & .32 & .30 & .56 \\
\hline France & .82 & .58 & .01 & .28 \\
\hline Germany & .28 & .33 & .14 & .07 \\
\hline
\end{tabular}

Table 1: Chow Test: The table shows the significance level, for each equation, for the null hypothesis that no structural break has taken place before and after 1981:1.

\begin{tabular}{|c|c|c|c|c|c|c|c|c|}
\hline Country & $b_{21}$ & $b_{12}$ & $3 / 4$ & $3 / 4$ & $b_{21} 3 / 41$ & $b_{12} 3 / 4$ & $\mathrm{i} \mathrm{B}_{21}(1)^{3 / 4}$ & $\mathrm{i} \mathrm{B}_{22}(1)^{3 / 4}$ \\
\hline U.S. & 60 & -1.23 & 0.003 & 0.290 & 0.18 & -0.36 & 0.351 & 0.712 \\
\hline U.S. & 30 & -1.22 & 0.006 & 0.291 & 0.19 & -0.36 & 0.331 & 0.715 \\
\hline U.S. & 1 & -1.02 & 0.105 & 0.333 & 0.105 & -0.340 & 0.121 & 0.780 \\
\hline U.K. & 60 & -1.21 & 0.003 & 0.108 & 0.18 & -0.13 & 0.975 & 1.12 \\
\hline U.K. & 30 & -1.18 & 0.005 & 0.110 & 0.15 & -0.13 & 0.954 & 1.139 \\
\hline U.K. & 1 & -0.642 & 0.071 & 0.171 & 0.071 & -0.110 & 0.238 & 1.466 \\
\hline Spain & 60 & -4.96 & 0.007 & 0.123 & 0.42 & -0.61 & 0.547 & 0.086 \\
\hline Spain & 30 & -4.76 & 0.014 & 0.128 & 0.42 & -0.61 & 0.545 & 0.092 \\
\hline Spain & 1 & -1.640 & 0.310 & 0.320 & 0.310 & -0.525 & 0.432 & 0.347 \\
\hline France & 60 & -1.21 & 0.003 & 0.169 & 0.18 & -0.20 & 0.288 & 0.329 \\
\hline France & 30 & -1.20 & 0.006 & 0.171 & 0.18 & -0.21 & 0.283 & 0.649 \\
\hline France & 1 & -0.801 & 0.090 & 0.229 & 0.090 & -0.184 & 0.119 & 0.421 \\
\hline Germany & 60 & -1.11 & 0.003 & 0.178 & 0.18 & -0.20 & 0.243 & 0.517 \\
\hline Germany & 30 & -1.09 & 0.006 & 0.180 & 0.18 & -0.20 & 0.236 & 0.520 \\
\hline Germany & 1 & -0.762 & 0.084 & 0.233 & 0.084 & -0.178 & 0.008 & 0.571 \\
\hline
\end{tabular}

Table 2: Standardization over $\mathrm{L}_{\mathrm{t}}$. The first four columns summarise the impact effects and standard deviations of the shocks, that is the coefficient $b_{12}, b_{21}, 3 / 41,3 / 4$ in the main text once a VAR with two lags is ran. The last two columns document the long run impacts on the unemployment measure. The term $B_{i j}(1)$ indicates the element in rows $i$ and column $j$ of the structural matrix polynomial $B(L)$ in equation (5) evaluated at $L=1$. Note: The elements in the first column of the matrix $B_{0}$ and $B(L)$ refer to the reallocative shock, the ones in the second to the aggregate shock. 


\begin{tabular}{|c|c|c|c|c|c|}
\hline Country & Specification & $1 \mathrm{st}$ & $2 \mathrm{nd}$ & $3 \mathrm{rd}$ & 4 th \\
\hline \multirow[t]{2}{*}{ U.S. } & & .567 & .480 & .427 & .427 \\
\hline & & .442 & .442 & .116 & .116 \\
\hline \multirow[t]{2}{*}{ U.K. } & & .889 & .550 & .550 & .289 \\
\hline & & .746 & .545 & .545 & .483 \\
\hline \multirow[t]{2}{*}{ Spain } & & .806 & .806 & .455 & .323 \\
\hline & & .805 & .805 & .471 & .426 \\
\hline \multirow[t]{2}{*}{ France } & & .815 & .815 & .602 & .419 \\
\hline & $\frac{T_{t}}{E_{t}} ;$ & .861 & .861 & .739 & .302 \\
\hline \multirow[t]{2}{*}{ Germany } & & .667 & .573 & .542 & .542 \\
\hline & $\frac{T_{t}}{E_{t}} ; \frac{\sigma_{t}}{U_{t}}$ & .759 & .759 & .433 & .223 \\
\hline
\end{tabular}

Table 3: Speed of adjustment ranking for the unemployment rate (ranked eigenvalues): two variables VAR. The entries show the values of the norm of the ranked eigenvalues of the VAR representation of the VAR for different specifications. All VAR are ran with two lags.

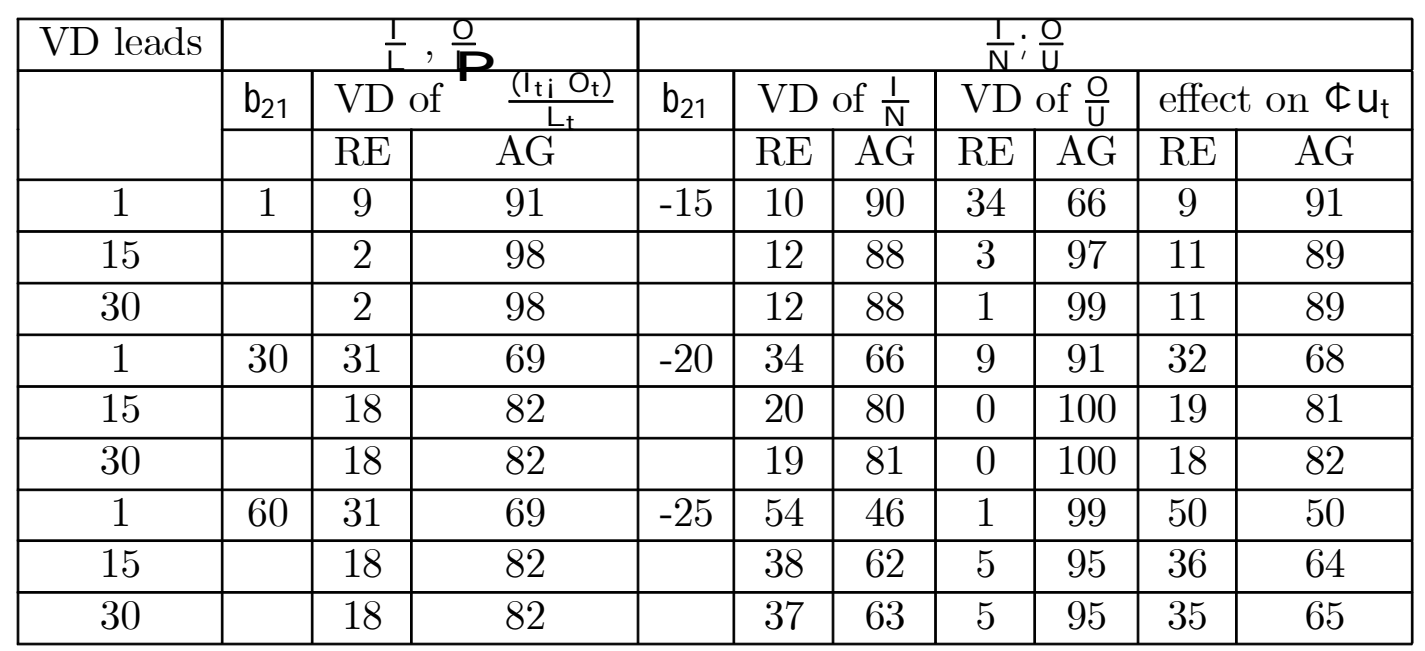

Table 4: Country: U.S. VD stands for forecasting variance decomposition of the (approximated) unemployment rate, $\mathrm{RE}$ for reallocative shock, $\mathrm{AG}$ for aggregate shock. For the specification with outflow and inflow rates, we also consider as a measure of the forecasting variance decomposition for the unemployment rate the average between the ones of inflow and outflow rate whith weight equal to $\left(1_{i} u_{t}\right)$ and $u_{t}$ respectively where a standardizing value of 0.07 is chosen for $u_{t}$. All VAR are ran with two lags. 


\begin{tabular}{|c|c|c|c|c|c|c|c|c|c|c|}
\hline VD leads & \multicolumn{3}{|c|}{$\frac{T}{L}, \frac{O}{D}$} & \multicolumn{7}{|c|}{$\frac{1}{N} ; \frac{O}{U}$} \\
\hline & \multirow[t]{2}{*}{$b_{21}$} & VD of & \multirow{2}{*}{$\frac{\frac{\left(I_{\left.\mathrm{ti} O_{\mathrm{t}}\right)}\right.}{L_{t}}}{\mathrm{AG}}$} & \multirow[t]{2}{*}{$b_{21}$} & \multicolumn{2}{|c|}{ VD of $\frac{1}{N}$} & \multicolumn{2}{|c|}{ VD of $\frac{O}{U}$} & \multicolumn{2}{|c|}{ effect on $\$ u_{t}$} \\
\hline & & $\mathrm{RE}$ & & & $\mathrm{RE}$ & $\mathrm{AG}$ & $\overline{\mathrm{RE}}$ & $\overline{A G}$ & $\mathrm{RE}$ & $\mathrm{AG}$ \\
\hline 1 & 1 & 15 & 85 & -10 & 0 & 100 & 94 & 6 & 7 & 93 \\
\hline 15 & & 3 & 97 & & 4 & 96 & 84 & 16 & 10 & 90 \\
\hline 30 & & 3 & 97 & & 5 & 95 & 82 & 18 & 10 & 90 \\
\hline 1 & 30 & 64 & 36 & -30 & 23 & 77 & 61 & 39 & 26 & 74 \\
\hline 15 & & 43 & 57 & & 6 & 94 & 44 & 56 & 9 & 91 \\
\hline 30 & & 42 & 58 & & 5 & 95 & 42 & 58 & 8 & 92 \\
\hline 1 & 60 & 66 & 34 & -60 & 62 & 38 & 23 & 77 & 59 & 41 \\
\hline 15 & & 45 & 55 & & 36 & 64 & 11 & 89 & 34 & 66 \\
\hline 30 & & 44 & 56 & & 34 & 66 & 9 & 91 & 32 & 68 \\
\hline
\end{tabular}

Table 5: Country: U.K. VD stands for forecasting variance decomposition of the (approximated) unemployment rate. For the specification with outflow and inflow rates, we also consider as a measure of the forecasting variance decomposition for the unemployment rate the average between the ones of inflow and outflow rate whith weight equal to $\left(1 ; u_{t}\right)$ and $u_{t}$ respectively where a standardizing value of 0.07 is chosen for $u_{t}$. All VAR are ran with two lags. 


\begin{tabular}{|c|c|c|c|c|c|c|c|c|c|c|}
\hline VD leads & \multicolumn{3}{|c|}{$\frac{T}{L}, \frac{O}{D}$} & \multicolumn{7}{|c|}{$\frac{1}{N} ; \frac{O}{U}$} \\
\hline & \multirow[t]{2}{*}{$b_{21}$} & VD of & \multirow{2}{*}{$\frac{\frac{\left(I_{\left.\mathrm{ti} O_{\mathrm{t}}\right)}\right.}{L_{t}}}{\mathrm{AG}}$} & \multirow[t]{2}{*}{$b_{21}$} & \multicolumn{2}{|c|}{ VD of $\frac{1}{N}$} & \multicolumn{2}{|c|}{ VD of $\frac{O}{U}$} & \multicolumn{2}{|c|}{ effect on $\$ u_{t}$} \\
\hline & & $\mathrm{RE}$ & & & $\mathrm{RE}$ & $\mathrm{AG}$ & $\mathrm{RE}$ & $\overline{A G}$ & $\mathrm{RE}$ & $\mathrm{AG}$ \\
\hline 1 & 1 & $\overline{48}$ & 52 & $\overline{-1}$ & 51 & 49 & 84 & 16 & 53 & $\overline{47}$ \\
\hline 15 & & 58 & 42 & & 71 & 29 & 83 & 17 & 72 & 28 \\
\hline 30 & & 59 & $\overline{41}$ & & 74 & 26 & 83 & 17 & 74 & 26 \\
\hline 1 & 30 & 92 & 8 & -30 & 83 & 17 & 51 & 49 & 81 & 19 \\
\hline 15 & & 95 & 5 & & 94 & 6 & 50 & 50 & 90 & 10 \\
\hline 30 & & 96 & 4 & & 96 & 4 & 50 & 50 & 93 & 7 \\
\hline 1 & 60 & 92 & 8 & -60 & 94 & 6 & 34 & 66 & 90 & 10 \\
\hline 15 & & 96 & 4 & & 98 & 2 & 33 & 67 & 93 & 7 \\
\hline 30 & & 97 & 3 & & 99 & 1 & 33 & 67 & 94 & 6 \\
\hline
\end{tabular}

Table 6: Country: Spain. VD stands for forecasting variance decomposition of the (approximated) unemployment rate. For the specification with outflow and inflow rates, we also consider as a measure of the forecasting variance decomposition for the unemployment rate the average between the ones of inflow and outflow rate whith weight equal to $\left(1 ; u_{t}\right)$ and $u_{t}$ respectively where a standardizing value of 0.07 is chosen for $u_{t}$. All VAR are ran with two lags. 


\begin{tabular}{|c|c|c|c|c|c|c|c|c|c|c|}
\hline VD leads & \multicolumn{3}{|c|}{$\frac{T}{L}, \frac{O}{D}$} & \multicolumn{7}{|c|}{$\frac{1}{N} ; \frac{O}{U}$} \\
\hline & \multirow[t]{2}{*}{$b_{21}$} & VD of & \multirow{2}{*}{$\frac{\frac{\left(I_{\left.\mathrm{ti} O_{\mathrm{t}}\right)}\right.}{L_{t}}}{\mathrm{AG}}$} & \multirow[t]{2}{*}{$b_{21}$} & \multicolumn{2}{|c|}{ VD of $\frac{1}{N}$} & \multicolumn{2}{|c|}{ VD of $\frac{O}{U}$} & \multicolumn{2}{|c|}{ effects on $\$ u_{t}$} \\
\hline & & $\mathrm{RE}$ & & & $\mathrm{RE}$ & $\mathrm{AG}$ & $\overline{\mathrm{RE}}$ & $\overline{\mathrm{AG}}$ & $\mathrm{RE}$ & $\mathrm{AG}$ \\
\hline 1 & 1 & 13 & 87 & -10 & 0 & 100 & 83 & 17 & 6 & $\overline{94}$ \\
\hline 15 & & 7 & 93 & & 2 & 98 & 60 & 40 & 6 & 94 \\
\hline 30 & & 7 & 93 & & 1 & 99 & 59 & $\overline{41}$ & 5 & 95 \\
\hline 1 & 30 & 52 & 48 & -30 & 47 & 53 & 17 & $\overline{83}$ & 45 & 55 \\
\hline 15 & & 42 & 58 & & 43 & 57 & 4 & 96 & 40 & 60 \\
\hline 30 & & 42 & 58 & & 41 & 59 & 3 & 97 & 38 & 62 \\
\hline 1 & 60 & 53 & 47 & -60 & 84 & 16 & 0 & 100 & 78 & 22 \\
\hline 15 & & 43 & 57 & & 79 & 21 & 6 & 94 & 74 & 26 \\
\hline 30 & & 43 & 57 & & 78 & 22 & 6 & 94 & 73 & 27 \\
\hline
\end{tabular}

Table 7: Country: France. VD stands for forecasting variance decomposition of the (approximated) unemployment rate. For the specification with outflow and inflow rates, we also consider as a measure of the forecasting variance decomposition for the unemployment rate the average between the ones of inflow and outflow rate whith weight equal to $\left(1 ; u_{t}\right)$ and $u_{t}$ respectively where a standardizing value of 0.07 is chosen for $u_{t}$. All VAR are ran with two lags. 


\begin{tabular}{|c|c|c|c|c|c|c|c|c|c|c|}
\hline \multirow[t]{3}{*}{ VD leads } & \multicolumn{3}{|c|}{$\frac{1}{L}, \frac{O}{D}$} & \multicolumn{7}{|c|}{$\frac{1}{N} ; \frac{O}{U}$} \\
\hline & \multirow[t]{2}{*}{$b_{21}$} & \multicolumn{2}{|c|}{ VD of } & \multirow[t]{2}{*}{$b_{21}$} & \multicolumn{2}{|c|}{ VD of $\frac{1}{N}$} & \multicolumn{2}{|c|}{ VD of $\frac{O}{U}$} & \multicolumn{2}{|c|}{ effects on $\phi u_{t}$} \\
\hline & & $\mathrm{RE}$ & $\mathrm{AG}$ & & $\overline{\mathrm{RE}}$ & $\overline{A G}$ & $\overline{\mathrm{RE}}$ & $\overline{\mathrm{AG}}$ & $\mathrm{RE}$ & $\mathrm{AG}$ \\
\hline$\overline{1}$ & 1 & 11 & 89 & -40 & $\overline{1}$ & 99 & 65 & 35 & 5 & 95 \\
\hline 15 & & 0 & 100 & & 2 & 98 & 41 & 59 & 5 & 95 \\
\hline 30 & & 0 & 100 & & 2 & 98 & 39 & 61 & 5 & 95 \\
\hline 1 & 30 & 47 & 53 & -50 & 7 & 93 & 49 & 51 & 10 & 90 \\
\hline 15 & & 18 & 82 & & 9 & 91 & 26 & 74 & 10 & 90 \\
\hline 30 & & 18 & 82 & & 9 & 91 & 24 & 76 & 10 & 90 \\
\hline 1 & 60 & 49 & 51 & -60 & 17 & 83 & 35 & 65 & 18 & 82 \\
\hline 15 & & 19 & 81 & & 19 & 81 & 15 & 85 & 19 & 81 \\
\hline 30 & & 19 & 81 & & 19 & 81 & 13 & 87 & 19 & 81 \\
\hline
\end{tabular}

Table 8: Country: Germany. VD stands for forecasting variance decomposition of the (approximated) unemployment rate. For the specification with outflow and inflow rates, we also consider as a measure of the forecasting variance decomposition for the unemployment rate the average between the ones of inflow and outflow rate whith weight equal to $\left(1 ; u_{t}\right)$ and $u_{t}$ respectively where a standardizing value of 0.07 is chosen for $u_{t}$. All VAR are ran with two lags. 


\begin{tabular}{|c|c|c|c|c|c|c|c|c|c|}
\hline \multirow[t]{3}{*}{ Country } & C.I. & \multicolumn{4}{|c|}{ Aggregate Shock } & \multicolumn{4}{|c|}{ Reall. Shock } \\
\hline & & \multicolumn{4}{|c|}{ Leads: } & \multicolumn{4}{|c|}{ Leads: } \\
\hline & & 2 & 5 & 15 & 30 & 2 & 5 & 15 & 30 \\
\hline \multirow[t]{2}{*}{ UK } & resp & 0.27 & 0.12 & -0.42 & -0.87 & -0.01 & -0.01 & -0.07 & -0.15 \\
\hline & $\operatorname{band}\left(\begin{array}{c}+ \\
i\end{array}\right)$ & 0.10 & 0.33 & 1.00 & 2.51 & 0.08 & 0.21 & 0.46 & 0.77 \\
\hline \multirow[t]{2}{*}{ Spain } & resp & 0.03 & 0.37 & 0.49 & 0.49 & -0.26 & -0.32 & -0.32 & -0.31 \\
\hline & $\operatorname{band}\left(\begin{array}{l}+ \\
i\end{array}\right)$ & 0.12 & 0.30 & 0.56 & 0.66 & 0.13 & 0.24 & 0.33 & 0.34 \\
\hline \multirow[t]{2}{*}{ France } & resp & 0.25 & 0.35 & 0.40 & 0.41 & 0.00 & -0.01 & 0.00 & 0.01 \\
\hline & $\operatorname{band}\left(\begin{array}{l}+ \\
i\end{array}\right)$ & 0.10 & 0.32 & 0.60 & 0.70 & 0.01 & 0.17 & 0.24 & 0.27 \\
\hline \multirow[t]{2}{*}{ Germany } & resp & 0.22 & 0.24 & 0.23 & 0.22 & 0.04 & 0.10 & 0.13 & 0.13 \\
\hline & $\operatorname{band}\left({ }^{+}\right)$ & 0.10 & 0.34 & 0.69 & 0.82 & 0.09 & 0.184 & 0.25 & 0.27 \\
\hline
\end{tabular}

Table 9: US vs Europe, Comparison of Impulse Responses: This table is for the specification over the labour force, with b21 $=1$. The first number in each box, represents the difference of the impulse response of the unemployment rate of the country, minus that of the US, calculated at different leads. The second, labelled band $\left({ }_{i}^{+}\right)$, is one half of the size of the corresponding $95 \%$ confidence interval. band $\left(\begin{array}{c}+ \\ i\end{array}\right)$ is calculated using a bootstrapping technique with 1000 replications. 


\begin{tabular}{|c|c|c|c|c|c|c|c|c|c|}
\hline Country & C.I. & \multicolumn{4}{|c|}{ Aggregate Shock } & \multicolumn{4}{|c|}{ Reallocative Shock } \\
\hline & & \multicolumn{4}{|c|}{ Leads: } & \multicolumn{4}{|c|}{ Leads: } \\
\hline & & 2 & 5 & 15 & 30 & 2 & 5 & 15 & 30 \\
\hline \multirow[t]{2}{*}{ UK } & resp & 0.31 & 0.21 & -0.23 & -0.62 & 0.01 & -0.11 & -0.48 & $\begin{array}{l}-0.79 \\
\end{array}$ \\
\hline & $\operatorname{band}\left(\begin{array}{c}+ \\
i\end{array}\right)$ & 0.09 & 0.33 & 0.93 & 2.25 & 0.09 & 0.23 & 0.71 & 1.78 \\
\hline \multirow[t]{2}{*}{ Spain } & resp & 0.22 & 0.57 & 0.69 & 0.70 & -0.32 & -0.24 & -0.20 & -0.20 \\
\hline & $\operatorname{band}\left(\begin{array}{l}+ \\
i\end{array}\right)$ & 0.12 & 0.28 & 0.53 & 0.65 & 0.12 & 0.28 & 0.46 & 0.54 \\
\hline \multirow[t]{2}{*}{ France } & resp & 0.26 & 0.37 & 0.41 & 0.42 & 0.04 & 0.05 & 0.06 & 0.06 \\
\hline & $\operatorname{band}\left(\begin{array}{c}+ \\
i\end{array}\right)$ & 0.09 & 0.30 & 0.55 & 0.65 & 0.09 & 0.21 & 0.37 & 0.43 \\
\hline \multirow[t]{2}{*}{ Germany } & resp & 0.22 & 0.23 & 0.20 & 0.18 & 0.06 & 0.10 & 0.11 & 0.10 \\
\hline & $\operatorname{band}\left(\begin{array}{c}+ \\
i\end{array}\right)$ & 0.10 & 0.33 & 0.71 & 1.26 & 0.10 & 0.23 & 0.41 & 0.60 \\
\hline
\end{tabular}

Table 10: US vs Europe, Comparison of Impulse Responses: The table is for the specification over the labour force, with b21 $=30$. The first number in each box, represents the difference of the impulse response of the unemployment rate of the country, minus that of the US, calculated at different leads. The second, labelled band $\left(\begin{array}{c}+ \\ i\end{array}\right)$, is one half of the size of the corresponding $95 \%$ confidence interval. band $\left(\begin{array}{c}+ \\ i\end{array}\right)$ is calculated using a bootstrapping technique with 1000 replications. 


\begin{tabular}{|c|c|c|c|c|c|c|c|c|c|}
\hline Country & C.I & \multicolumn{4}{|c|}{ Aggregate Shock } & \multicolumn{4}{|c|}{ Reallocative Shock } \\
\hline & & \multicolumn{4}{|c|}{ Leads: } & \multicolumn{4}{|c|}{ Leads: } \\
\hline & & 2 & 5 & 15 & 30 & 2 & 5 & 15 & 30 \\
\hline \multirow[t]{2}{*}{$\overline{\mathrm{UK}}$} & resp & 0.31 & 0.23 & -0.17 & -0.50 & 0.01 & -0.11 & -0.47 & -0.75 \\
\hline & $\operatorname{band}\left(\begin{array}{c}+ \\
i\end{array}\right)$ & 0.10 & 0.34 & 0.91 & 1.91 & 0.09 & 0.23 & 0.71 & 1.58 \\
\hline \multirow[t]{2}{*}{ Spain } & resp & 0.23 & 0.57 & 0.69 & 0.69 & -0.31 & -0.24 & -0.20 & -0.20 \\
\hline & $\operatorname{band}\left(\begin{array}{l}+ \\
i\end{array}\right)$ & 0.13 & 0.27 & 0.47 & 0.51 & 0.12 & 0.27 & 0.41 & 0.43 \\
\hline \multirow[t]{2}{*}{ France } & resp & 0.26 & 0.37 & 0.41 & 0.41 & 0.03 & 0.04 & 0.06 & 0.06 \\
\hline & $\operatorname{band}\left(\begin{array}{l}+ \\
i\end{array}\right)$ & 0.10 & 0.29 & 0.51 & 0.57 & 0.09 & 0.21 & 0.36 & 0.39 \\
\hline \multirow[t]{2}{*}{ Germany } & resp & 0.22 & 0.22 & 0.20 & 0.19 & 0.06 & 0.10 & 0.10 & 0.10 \\
\hline & $\operatorname{band}\left(\left(^{+}\right)\right.$ & 0.10 & 0.32 & 0.64 & 0.76 & 0.09 & 0.22 & 0.38 & 0.43 \\
\hline
\end{tabular}

Table 11: US vs Europe, Comparison of Impulse Responses: The table is for the specification over the labour force, with b21 $=60$. The first number in each box, represents the difference of the impulse response of the unemployment rate of the country, minus that of the US, calculated at different leads. The second, labelled band $\left(\begin{array}{c}+ \\ i\end{array}\right)$, is one half of the size of the corresponding $95 \%$ confidence interval. band $\left(\begin{array}{c}+ \\ i\end{array}\right)$ is calculated using a bootstrapping technique with 1000 replications. 


\begin{tabular}{|c|c|c|c|c|c|c|}
\hline Country & $\begin{array}{l}\text { Number of } \\
\text { Variables }\end{array}$ & Leads: & $\begin{array}{l}\text { Aggr. } \\
\text { shock }\end{array}$ & $\begin{array}{l}\text { Reall. } \\
\text { shock }\end{array}$ & $\begin{array}{l}\text { Skill Mism. } \\
\text { shock }\end{array}$ & $\begin{array}{l}\text { Skill Neutr. } \\
\text { shock }\end{array}$ \\
\hline \multirow[t]{3}{*}{ U.S. } & \multirow[t]{3}{*}{3 Vars. } & 1 & 0.96 & 0.02 & - & 0.02 \\
\hline & & 15 & 0.99 & 0.01 & - & 0.00 \\
\hline & & 30 & 1.00 & 0.00 & - & 0.00 \\
\hline \multirow[t]{3}{*}{ U.S. } & \multirow[t]{3}{*}{ 4Vars. } & 1 & 0.95 & 0.02 & 0.02 & 0.01 \\
\hline & & 15 & 0.95 & 0.01 & 0.04 & 0.00 \\
\hline & & 30 & 0.95 & 0.01 & 0.04 & 0.00 \\
\hline \multirow[t]{3}{*}{ U.K. } & \multirow[t]{3}{*}{3 Vars. } & 1 & 0.51 & 0.46 & - & 0.03 \\
\hline & & 15 & 0.72 & 0.28 & - & 0.00 \\
\hline & & 30 & 0.74 & 0.26 & - & 0.00 \\
\hline \multirow[t]{3}{*}{ U.K. } & \multirow[t]{3}{*}{4 Vars. } & 1 & 0.51 & 0.43 & 0.04 & 0.02 \\
\hline & & 15 & 0.71 & 0.27 & 0.02 & 0.00 \\
\hline & & 30 & 0.72 & 0.25 & 0.03 & 0.00 \\
\hline \multirow[t]{3}{*}{ Spain } & \multirow[t]{3}{*}{3 Vars. } & 1 & 0.77 & 0.22 & - & 0.01 \\
\hline & & 15 & 0.65 & 0.34 & - & 0.01 \\
\hline & & 30 & 0.65 & 0.35 & - & 0.00 \\
\hline \multirow[t]{3}{*}{ Spain } & \multirow[t]{3}{*}{4 Vars. } & 1 & 0.34 & 0.25 & 0.39 & 0.02 \\
\hline & & 15 & 0.41 & 0.21 & 0.37 & 0.01 \\
\hline & & 30 & 0.42 & 0.21 & 0.37 & 0.00 \\
\hline \multirow[t]{3}{*}{ France } & \multirow[t]{3}{*}{3 Vars. } & 1 & 0.64 & 0.31 & - & 0.05 \\
\hline & & 15 & 0.63 & 0.36 & - & 0.01 \\
\hline & & 30 & 0.63 & 0.37 & - & 0.00 \\
\hline \multirow[t]{3}{*}{ France } & \multirow[t]{3}{*}{4 Vars. } & 1 & 0.65 & 0.01 & 0.30 & 0.04 \\
\hline & & 15 & 0.64 & 0.13 & 0.23 & 0.00 \\
\hline & & 30 & 0.64 & 0.13 & 0.23 & 0.00 \\
\hline \multirow[t]{3}{*}{ Germany } & \multirow[t]{3}{*}{3 Vars. } & 1 & 0.56 & 0.42 & - & 0.02 \\
\hline & & 15 & 0.80 & 0.19 & - & 0.01 \\
\hline & & 30 & 0.80 & 0.19 & - & 0.01 \\
\hline \multirow[t]{3}{*}{ Germany } & \multirow[t]{3}{*}{4 Vars } & 1 & 0.59 & 0.21 & 0.18 & 0.02 \\
\hline & & 15 & 0.71 & 0.22 & 0.06 & 0.01 \\
\hline & & 30 & 0.71 & 0.22 & 0.06 & 0.01 \\
\hline
\end{tabular}

Table 12: Forecast Variance Decomposition of the Unemployment rate (three and four Variables VAR). The coefficient $b_{21}$ is chosen to be equal to 30. All VAR are ran with two lags. 


\begin{tabular}{|l|l|l|l|l|l|l|l|l|c|}
\hline Country & $\begin{array}{l}\text { N. of } \\
\text { Var. }\end{array}$ & 1 st & 2nd & 3rd & 4 th & 5 th & 6 th & 7 th & 8 th \\
\hline U.S. & 3 vars. & .616 & .552 & .455 & .455 & .358 & .111 & - & - \\
& 4 vars. & .684 & .684 & .664 & .535 & .535 & .323 & .323 & .016 \\
\hline U.K. & 3 vars. & .888 & .484 & .467 & .467 & .234 & .160 & - & - \\
& 4 vars. & .890 & .494 & .494 & .407 & .360 & .360 & .342 & .342 \\
\hline Spain & 3 vars. & .857 & .857 & .537 & .486 & .486 & .456 & - & - \\
& 4 vars. & .881 & .881 & .638 & .601 & .556 & .556 & .479 & .479 \\
\hline France & 3 vars. & .823 & .823 & .472 & .221 & .221 & .215 & - & - \\
& 4 vars & .804 & .804 & .763 & .763 & .556 & .556 & .361 & .331 \\
\hline Germany & 3vars. & .662 & .627 & .627 & .596 & .375 & .031 & - & - \\
& 4 vars. & .832 & .832 & .682 & .617 & .617 & .589 & .398 & .062 \\
\hline
\end{tabular}

Table 13: Speed of adjustment ranking for the unemployment rate (ranked eigenvalues): three and four variables VAR. The entries have the same meaning as the ones in the two variable case (table 6). All VAR are ran with two lags. 